\title{
EL GÉNERO PROSOPIS, VALIOSO RECURSO FORESTAL DE LAS ZONAS ÁRIDAS Y SEMIÁRIDAS DE AMÉRICA, ASIA Y AFRICA.
}

Santiago Barros. Ingeniero Forestal. Instituto Forestal, Chile. sbarros@infor.cl

\section{RESUMEN}

El género Prosopis, familia Leguminosae o Fabaceae, subfamilia Mimosoideae, está presente en forma natural en las zonas áridas y semiáridas de África, América y Asia. Consta de 44 especies, arbustivas y arbóreas, que taxonómicamente han sido divididas en 5 secciones. Tres especies son nativas de Asia, una de África y las restantes cuarenta de América, principalmente Sudamérica. Se las conoce con diferentes nombre vernáculos locales; en América, algarrobo, mezquite, Mesquite, Screwbean.

Son especies multipropósito, la mayoría espinosas, alrededor de la mitad de ellas superan los $7 \mathrm{~m}$ de altura y varias llegan a 15 y $20 \mathrm{~m}$ de altura. Son resistentes a extremas condiciones de sitio; sequía, calor, salinidad en el suelo, y todas ellas son fijadoras de nitrógeno.

Sus principales productos son combustible, en forma de leña y carbón de muy buena calidad, y forraje, por medio de su follaje y brotes tiernos y principalmente sus frutos. Según la especie se puede obtener madera para estructuras e incluso para aserrío, de gran calidad para muebles, parqué y otros usos, alimento humano en algunos casos, tinturas, curtientes, gomas, fibras y productos medicinales.

Estas características hacen de estas especies un recurso de mucho interés para zonas áridas y semiáridas, razón por la que se las ha introducido mediante plantaciones fuera de sus regiones de distribución natural. Especies como Prosopis juliflora y P. pallida, de América han sido introducidas en el NE de Brasil, en diversos países de África y Asia, y en Australia. Prosopis velutina y P. glandulosa, de Norteamérica, se han introducido en Australia y Sudáfrica, y en algunos casos en sus áreas de origen se están realizando plantaciones de cierta extensión con las especies nativas, como es el caso de Chile con Prosopis tamarugo y P. alba.

Varias de las principales especies del género son de carácter pionero, en especial Prosopis glandulosa y P. juliflora, y pueden tornarse agresivamente invasoras en sus lugares de origen y en especial en aquellos donde se las introduce, situación que hace muy importante un adecuado manejo y utilización de las plantaciones para evitar una dispersión descontrolada.

\section{SUMMARY}

The Prosopis genus, family Leguminosae or Fabaceae, sub family Mimosoideae, is naturally distributed on the arid and semiarid zones of Africa, Asia y America and is composed by 44 trees or shruby species, three of them native to Asia, one native to Africa and forty native to America, meanly South America. They are locally known as algarrobo, mesquite, Mesquite, Srewbean in America.

Prosopis species are multipurpose trees and shrubs, most of them thorny, about half of 
them reach more than $7 \mathrm{~m}$ heigh and several can reach up to 15 and $20 \mathrm{~m}$ heigh. The species are hot, drought and salt resistant, all are nitrogen fixing and thrive under extremely rigorous site conditions.

Main products from Prosopis species are fuel, through high quality firewood and charcoal, and fodder, from the leaves and fresh sprouts and meanly the pods. Depending on the species, there are several other valuable products, as wood for structure, fine furniture and floors, fencing material and others, human food in some cases, tannins, dyes, gums, fiber and medicinal products.

The above characteristics turn these species into interesting resources to arid and semiarid zones and they have been introduced by planting to areas out of their natural range. Prosopis juliflora and P. pallida, from America, have been introduced to NE Brazil, several countries in Africa and Asia, and to Australia also. Prosopis velutina and P. glandulosa, from Northamerica, were introduced to Australia and Southafrica, and within its natural range some species are used in afforestation programs, as in northern Chile with Prosopis tamarugo and $P$. alba.

Some of the main species in the genus have a pioneer character, especially Prosopis glandulosa and $P$. juliflora, and can become aggressive invader species within their native range and mainly through the exotic or introduction range. The risk of an out of control species spread has to be avoided by means of forest management and appropriate use of the species in the new areas.

\section{INTRODUCCIÓN}

Las especies del género Prosopis, familia Leguminosae o Fabaceae, subfamilia Mimosoideae, se distribuyen naturalmente en la zonas áridas y semiáridas de Asia, África y América, se han clasificado 44 especies en el género, agrupadas en cinco series (Burkart, 1976).

Es un género principalmente americano, sólo 3 especies son nativas de Asia y una de África, las restantes 40 se distribuyen en Norteamérica, Centroamérica y, mayoritariamente, Sudamérica.

Se trata en general de especies arbustivas y arbóreas, espinosas, fijadoras de nitrógeno y resistentes a calor, frío, salinidad en el suelo y sequía, que ofrecen una variedad de productos, como madera, leña, carbón, alimentos, forraje y productos químicos. Alrededor de la mitad de ellas alcanzan alturas por sobre los $7 \mathrm{~m}$.

La más importantes por su distribución, tamaño y productos son probablemente Prosopis cineraria, en Asia; Prosopis africana, en África; Prosopis velutina, P. glandulosa y P. laevigata, en Norteamérica; Prosopis juliflora, en Centroamérica; y Prosopis juliflora, P. pallida, P. nigra, $P$. alba, $P$. flexuosa, $P$. chilensis, $P$. tamarugo y $P$. caldenia, en Sudamérica.

Sus características de especies multipropósito, principalmente en términos de 
combustible, forraje y protección de suelos, que prosperan en condiciones de sitio bajo las cuales pocas otras especies de interés, o ninguna, lo hacen, las han tornado muy atractivas, tanto en sus áreas de origen como fuera de estas, y ya desde el Siglo XIX han sido introducidas muchas de ellas en zonas áridas y semiáridas del mundo fuera de sus áreas de distribución natural.

Las principales introducciones se han llevado a cabo con Prosopis juliflora y P. pallida, en zonas tropicales, y con Prosopis glandulosa y $P$. velutina, en zonas subtropicales. Prosopis alba y $P$. chilensis, han sido introducidos también en diferentes regiones, y con Prosopis cineraria, $P$. pubescens, $P$. africana y $P$. tamarugo se han realizado múltiples esfuerzos de introducción en diferentes lugares, pero raramente sobreviven, muy probablemente debido a las particulares condiciones de sitio bajo las cuales prosperan en forma natural, en especial Prosopis tamarugo.

Pasiecznik et al. (2001) comentan que en África se han introducido especies del género en 25 países; Marruecos, Argelia, Tunes, Libia y Egipto, en el norte; toda la región de Sahel, en el centro y oeste; Kenya y Tanzania, en el este; y Namibia, Zimbawe y Sudáfrica, en el sur.

Burkart (1976) señala que en Asia y el norte de África se han introducido Prosopis pallida, en India; Prosopis juliflora, en Irak, Pakistan, India y Vietnam; Prosopis glandulosa en Arabia, Pakistán e India; Prosopis juliflora en África Tropical; Prosopis pubescens, P. chilensis y P. glandulosa, en el sur y suroeste de África; Prosopis juliflora y en Hawaii, Islas Marquesas y Filipinas; y Prosopis juliflora, P. pallida, P. chilensis, P. glandulosa y P. velutina, en Australia.

Varias especies del género, y entre ellas aquellas que más se han difundido fuera de sus regiones de distribución natural, son especies pioneras de carácter invasor en sus áreas de ocurrencia natural, en especial Prosopis glandulosa, en USA y México; Prosopis juliflora, en Venezuela y Colombia; y Prosopis velutina, en USA; y han mantenido este comportamiento en las zonas en que se las ha introducido, invadiendo en algunos casos grandes extensiones de terreno y perjudicando la agricultura y la ganadería al formar densos matorrales espinosos que impiden el crecimiento de pastos y el ingreso de ganado o afectan napas y otros recursos de aguas. A las anteriores se agrega Prosopis pallida, que sin exhibir esta característica en sus áreas de ocurrencia natural, si lo hace donde se la ha introducido.

Es así como, además de USA, Australia, Sudáfrica y Namibia tienen problemas con Prosopis glandulosa; Australia, varios países de África, e islas del Caribe y del Atlántico, los tienen con Prosopis juliflora; Australia y las Islas Hawaii, con Prosopis pallida; y Australia y Sudáfrica, con Prosopis velutina. En varios de estos casos, las especies han llegado a ser consideradas malezas indeseables que deben ser combatidas o erradicadas.

No obstante, las especies del género proporcionan en diversas regiones del mundo, como especies nativas o introducidas, valiosos bienes y servicios, constituyendo en algunos casos la única especie arbórea y la única fuente de combustible y forraje.

Pasiecznik et al. (2001) señalan que la aceptación o valoración de estas especies se relaciona con los ingresos; quienes pueden comprar gas envasado para cocinar y no están obligados a criar ganado para subsistir, rápidamente olvidan el valor de estas especies como 
fuente de energía y forraje, sin embargo para los más pobres son un recurso único y valioso.

Los mismos autores señalan que, en contraste con visiones negativas sobre los algarrobos o mezquites, hasta el $70 \%$ de las necesidades de leña de poblaciones rurales en las zonas secas de India lo proveen formaciones de Prosopis; que en Hawaii Prosopis pallida es aún considerado el más valioso árbol introducido a las islas; que la misma especie en África ha probado ser muy útil en las zonas áridas de Sudán, al igual que en el oeste de África, como estabilizadora de dunas, y en la Región de Sahel formando cortinas cortavientos y cercos vivos, y como productora de combustible.

En términos generales, en las áreas donde los Prosopis son nativos hay cierto respeto por el árbol y sus productos, las especies han sido más estudiadas y hay por tanto mayor conocimiento sobre el valor de ellas. Sin embargo, esto ha conducido a sobreexplotación y agotamiento de las formaciones naturales en el pasado. En donde estas especies son introducidas, no hay conocimiento sobre su potencial y no hay responsabilidad en su uso y manejo, son subutilizadas y los recursos desperdiciados, situación que conduce a una dispersión, natural o inducida por el hombre, que sale de control y las especies se tornan invasoras.

Existen entonces recursos de importancia en diversas áreas del mundo, donde las especies son nativas y donde son exóticas, y los árboles son utilizados para madera de diferentes aplicaciones, como estructuras, leña, carbón, cercos y en algunos casos muebles y parqué; frutos y follaje para forraje; alimentos; medicinas; y otros productos y servicios.

Las administraciones forestales, las organizaciones internacionales y los particulares, siguen promocionando y plantando especies del género, con fines tanto productivos como de protección. Hay muchos casos de plantaciones de significación donde los propietarios reportan sólo diversos beneficios del recurso creado. En consecuencia varias especies del género continúan siendo consideradas y difundidas como especies multipropósito valiosas para zonas áridas y semiáridas.

\section{LAS LEGUMINOSAS}

Las leguminosas (Leguminosae) o fabáceas (Fabaceae) (ICBN, 2005) son una amplia familia de especies arbóreas, arbustivas y herbáceas, que fácilmente son reconocidas por sus frutos tipo legumbre y sus hojas compuestas y estipuladas. Es una familia de distribución cosmopolita con más de 700 géneros y más de 19.000 especies, lo que la convierte en la tercera familia con mayor riqueza de especies después de las compuestas (Asteraceae) y las orquídeas (Orchidaceae) (Stevens, 2001).

A esta familia corresponde alrededor del $16 \%$ de las especies arbóreas de los bosques lluviosos neotropicales, es la familia más representada en los bosques tropicales lluviosos y en los bosques secos de América y África (Burnham and Johnson, 2004. en Wikipedia, 2010), y está subdividida en tres subfamilias; Caesalpinioideas, Mimosoideas y Faboideas (Papilionoideas), siendo las dos últimas las que concentran la mayor riqueza de especies

Las leguminosas presentan una gran variedad de hábitos de crecimiento, desde arbóreo, 
arbustivo y herbáceo hasta enredaderas herbáceas y lianas. En el caso de las herbáceas, estas pueden ser anuales, bianuales o perennes. Las hojas son casi siempre alternas y con estípulas, persistentes o caducas, generalmente compuestas, pinnadas o bipinnadas, digitadas o trifoliadas, a veces aparentemente simples unifoliadas o ausentes, caso en el que los tallos se han transformados en filodios. Es frecuente la presencia de espinas por transformación del raquis de las hojas, de las estípulas o del tallo.

Las raíces presentan un predominio del sistema primario que proviene de la radícula del embrión, son a menudo profundas y casi siempre tienen nódulos poblados de bacterias del género Rhizobium, que asimilan el nitrógeno atmosférico y lo fijan en el suelo. Las flores son desde pequeñas a grandes, actinomorfas en el caso de las Mimosoideas, a leves o profundamente cigomorfas como en las Faboideas o Papilionoideas y en la mayor parte de las Caesalpinioideas. Las flores son solitarias o pueden disponerse en diversos tipos de inflorescencias, como racimos terminales o axilares, cabezuelas y umbelas.

El fruto de las leguminosas, legumbre, deriva de un ovario compuesto por un sólo carpelo que en la madurez se abre longitudinalmente en dos valvas, su dehiscencia ocurre por la nervadura media y por la unión carpelar. Sin embargo, existe una gran variedad de formas y tamaños de frutos en la familia, hay especies con frutos con tendencia a la indehiscencia, en otros casos el cáliz se transforma en una estructura de dispersión. Una liana tropical centroamericana (Entada gigas) produce una legumbre que llega a medir hasta 1,5 m de longitud, en tanto que la especie sudamericana Tipuana tipu ha modificado parte de la pared del fruto transformándolo en una sámara que es distribuida por el viento. Las semillas acumulan en los cotiledones almidón y proteínas, a veces aceites o aceites y proteínas. Lo más característico es la presencia de grandes cotiledones ricos en reservas, a menudo oleaginosas.

Caesalpinioideas: Son árboles y arbustos, a veces hierbas o trepadoras. Las hojas son pinnadas o bipinnadas. Habitan preferentemente en las regiones cálidas, y están muy bien representadas en las regiones tropicales de África y América, donde son especies a menudo gigantescas.

La subfamilia está compuesta por 160 géneros y aproximadamente 1.930 especies. Los géneros más representados son Senna ${ }^{1}$ (350 especies), Chamaechrista (265) y Caesalpinia (100).

Especies predominantemente tropicales, especialmente en África y América (Stevens, 2001). Es la subfamilia más primitiva, en ella se encuentran árboles como tara (Caesalpinia spinosa), árbol de Judea (Cersis siliquastrum), parkinsonia o palo verde (Parkinsonia aculeata), árbol de las tres espinas (Gleditsia triacanthos) y algarrobo europeo (Ceratonia siliqua).

Mimosoideas: Son árboles o arbustos, rara vez hierbas, de follaje grácil por sus hojas bipinnadas, raramente pinnadas o reducidas a filodios. En muchos casos

1-Originalmente para Linnaeus en Species Plantarum (1753), lo que hoy se conoce como Senna y Chamaecrista correspondía al género Cassia. Philip Miller separó Senna de Cassia en 1754 en la cuarta edición de The Gardeners Dictionary. Hoy muchos autores, siguiendo a Linnaeus, no reconocen los géneros Senna y Chamaecrista y los incluyen en Cassia. Esta situación hasta ahora no está resuelta. 
son espinosos y de aspecto muy particular por las pequeñas flores agregadas en cabezuelas o espigas.

Subfamilia formada por 82 géneros y unas 3.275 especies. Los géneros con mayor cantidad de especies son Acacia (960 especies), Mimosa (480), Inga (350), Calliandra (200), Vachellia (antes Acacia ${ }^{2}$ ) (161), Senegalia (antes Acacia) (85), Prosopis (45) y Pithecellobium (40).

Géneros principalmente de clima tropical y templado cálido, especialmente en África y América (Stevens, 2001). En esta subfamilia se encuentra un gran número de árboles y arbustos de zonas áridas y semiáridas, como las acacias o Wattles de Australia y los árboles paragua de África (Acacia spp.), y los Algarrobos de Suramérica y los mesquites de Norteamérica (Prosopis spp.).

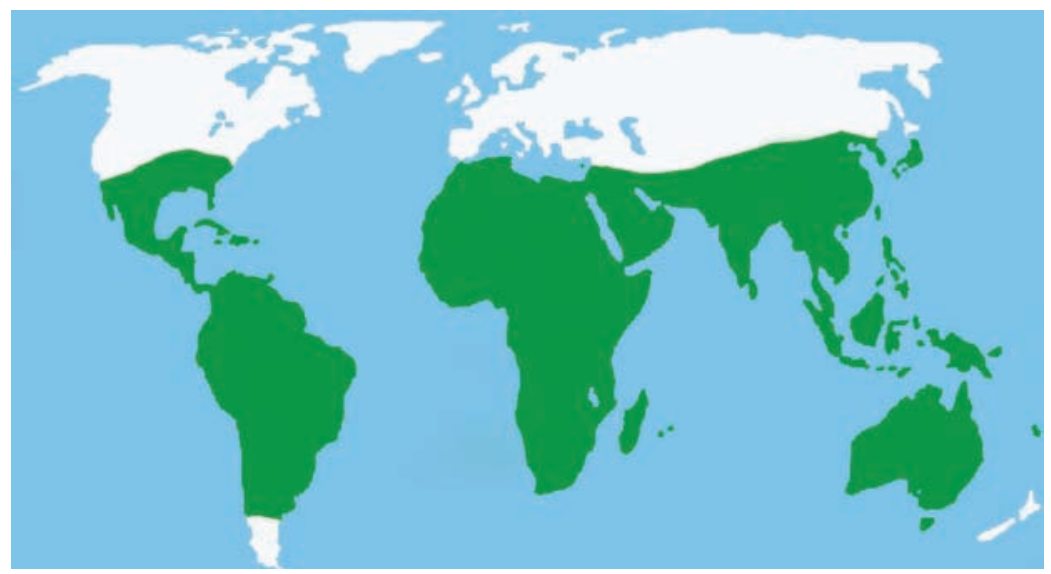

(Adaptado de Vester 1940; Maslin et al. 2003. Cit. por Stevens, 2001)

Figura $N^{\circ} 1$

DISTRIBUCIÓN SUBFAMILIA MIMOSOIDEAS

Faboideas (Papilionoideas): Son árboles, arbustos, trepadoras leñosas o herbáceas perennes o anuales. Las hojas son, por lo general, pinnadas o digitadas, frecuentemente trifoliadas, algunas veces unifoliadas y hasta nulas, pero nunca bipinnadas. Las flores se disponen en racimos, panojas, capítulos o espigas.

Es la división más grande y diversa de la familia. Se extiende por todos los continentes excepto las regiones árticas e incluye la mayoría de las leguminosas más populares utilizadas como alimento o forraje.

Subfamilia representada por 476 géneros y alrededor de 13.855 especies. Los géneros más representados son Astragalus (2400 a 3270 especies), Indigofera (700), Crotalaria (700),

2-Hay una larga discusión entre los botánicos; los especialistas australianos y africanos se han opuesto a segregar nuevos géneros desde Acacia para no cambiar el nombre a sus tradicionales acacias. Al haberse impuesto la segregación de Vachellia y Senegalia, se ha conservado el nombre acacia para la mayoría de las australianas, pero ha cambiado el de muchas otras del resto del mundo, y el género Acacia ha reducido su número de especies de más de 1.300 a 960 . 
Mirbelia (450) y otras, entre las que se encuentran Adesmia (240), Trifolium (240), Lupinus (200), Erythrina (110), Genista (90), Medicago (85), Cytisus (65), Phaseolus (60), Psoralea (50) y Sophora (50) (Stevens, 2001).

Géneros especialmente de clima templado y templado cálido, pero distribuido en todo el mundo (Stevens, 2001). Esta subfamilia incluye muchas leguminosas anuales de importancia económica como poroto (Phaseolus vulgaris), soya (Glycine max), alfalfa (Medicago sativa) y otras, y algunas leguminosas arbóreas como acacia falsa (Robinia pseudoacacia).

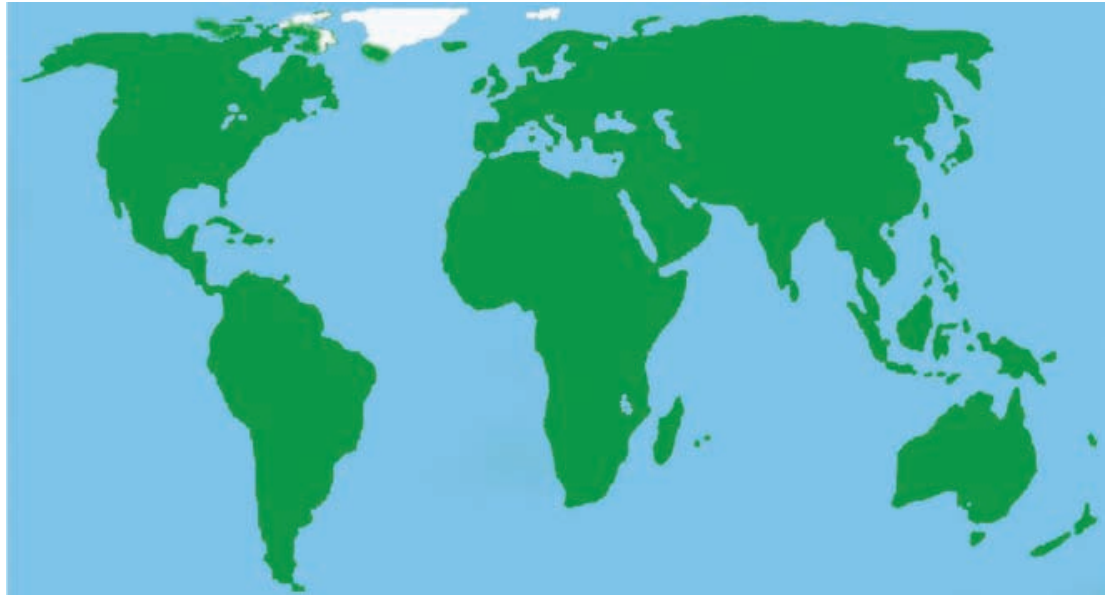

(Adaptado de Vester 1940; Meusel et al. 1965; Hultén 1971. Cit. por Stevens, 2001)

Figura $\mathrm{N}^{\circ} 2$

\section{DISTRIBUCIÓN SUBFAMILIA FABOIDEAS}

La cantidad de especies que la componen, la gran variedad de productos que estas ofrecen, en forma natural o bajo cultivo, y su distribución cosmopolita otorgan a la familia una gran importancia económica, en términos de alimentos, forraje, dendroenergía, protección y mejoramiento de suelos, ornamentación y una cantidad de productos industriales, como madera, celulosa, gomas, tinturas, curtientes, aceites y muchos otros.

\section{EL GÉNERO PROSOPIS - SUBFAMILIA MIMOSOIDEAS}

Los géneros Prosopis y Acacia contienen algunas de las especies más importante y de más amplia distribución en las zonas áridas y semiáridas tropicales y subtropicales del mundo. Se estima que especies de estos dos géneros ocupan unos 310 millones de hectáreas (Griffith, 1961. Cit. por Pasiecznik et al., 2001).

El nombre Prosopis fue dado al género por Linnaeus ${ }^{3}$ en 1767 para describir la única especie que en el momento conocía, Prosopis spicigera Linnaeus, hoy sinónimo con Prosopis cineraria (L.) Druce, la especie tipo del género.

3- Carlos Linneo (Råshult, Suecia, 23 de mayo de $\underline{1707}$ - Uppsala, 10 de enero de 1778). Científico, naturalista, botánico y zoólogo sueco que sentó las bases de la taxonomía moderna. 


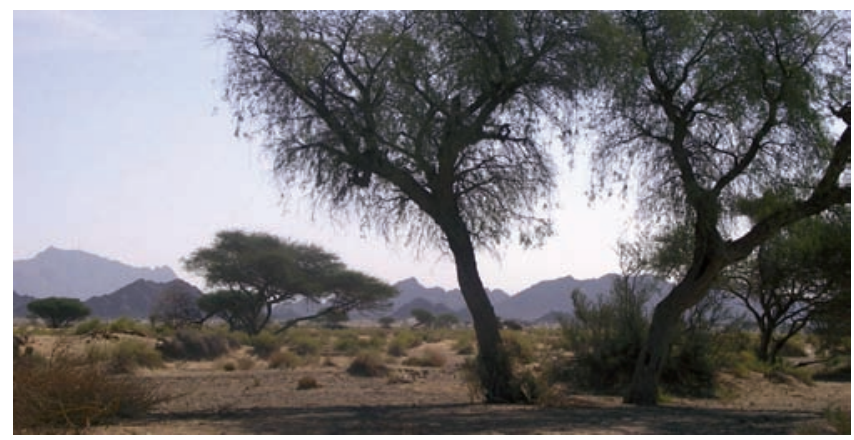

Figura $N^{\circ} 3$

Prosopis cineraria QATAR, GOLFO PËRSICO

Las especies del género son árboles y arbustos semideciduos, fijadores de nitrógeno, muy resistentes a sequía, calor, salinidad y alcalinidad, arena en movimiento, pastoreo y sucesivas cortas, muchas de ellas también al frío, características que las hacen particularmente valiosas en zonas áridas y semiáridas (Beresford-Jones, 2004). Se agrega a esto que la semilla contenida en los frutos consumidos por los animales resiste el paso por el tracto digestivo, donde los ácidos gástricos ablandan la testa, confiriéndole un tratamiento pregerminativo que la deja en condiciones de germinar de inmediato, cuando es expulsada con las fecas, si encuentra condiciones favorables de suelo y humedad.

Burkart (1976) señala que las especies del género son todas árboles o arbustos, raramente sub arbustos, de tamaño variable, xerófíticos, espinosos o raramente sin espinas.

Las hojas son bipinnadas con pocos pares de pinnas opuestas, los folíolos son pequeños, numerosos, principalmente opuestos, lineares, oblongos, fusiformes y de igual color por ambos lados. La nervadura es pinnada y no muy prominente. Los brotes en la mayoría de las especies son dimórficos con largos megablastos, flexibles y se tornan nudosos con la edad. Braquiblastos o cortos brotes emergen desde múltiples yemas axilares y desde estos se desarrollan (cuando existen) también las espinas (Pasiecznik et al., 2001).

Las flores son pequeñas, actinomorfas y hermafroditas, el cáliz es campanulado, la corola tiene pétalos lineares fusionados o más o menos libres, glabros o pubescentes. El androceo tiene 5+5 estambres libres, las anteras son elípticas y los granos de polen son simples, grandes o pequeños. Los racimos son puntiagudos, amentiformes, axilares, en la mayoría de los casos densos, pero en algunos casos en cabezas globosas.

El fruto es una legumbre carnosa, indehiscente, linear, angosta, falcada, anular a enrollada en espiral, con un mesocarpo carnoso, azucarado, fibroso y dividido en segmentos coriáceos de una semilla. Las semillas son ovoides, duras, café, con un endosperma mucilaginoso rodeando el embrión. Los cotiledones son planos, redondeados y epigeos en la germinación. 


\section{Clasificación Taxonómica}

Burkart (1976) reconoce y describe en el género 44 especies y las agrupa en 5 Secciones que se diferencian básicamente por la presencia, tipo y distribución de espinas.

La distribución natural del género es predominantemente americana, con 40 especies, pero está presente también en Asia, con tres especies, y en África, con una. A través de esta amplia distribución los nombres vernáculos locales son muy variados, pero los más comunes son algarrobo en Sudamérica y Mesquite (inglés) o mezquite (español) en Norteamérica. Algunas especies reciben también los nombres Screwbeanm, tornillo o mastuerzo, en América, debido a sus legumbres enrolladas en densas espirales (Pasiecznik et al., 2001).

\section{Familia: Leguminosae o Fabaceae}

\section{Sub Familia: Mimosoideae}

\section{Género: Prosopis (L.)}

I. Sección Prosopis. Arbustos o pequeños árboles, con espinas internodulares. SW de Asia y $\mathrm{N}$ de África. 3 especies.

P. cineraria (L.) Druce

P. farcta (Solander ex Russell) Mac Bride var. farcta var. glabra Burkart

P. koelziana Burkart

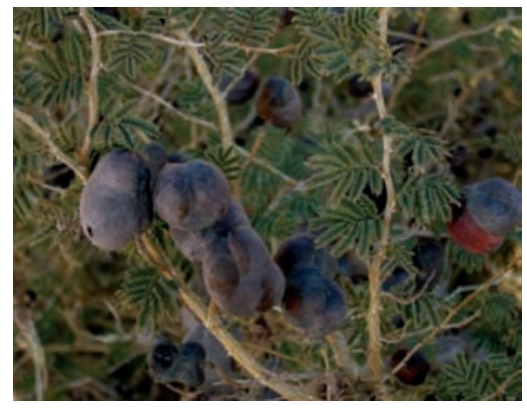

Prosopis farcta

II. Sección Anonychium. Árboles sin espinas. África Tropical. 1 especie.

P. africana (Guill., Perr. \& Rich.) Taubert

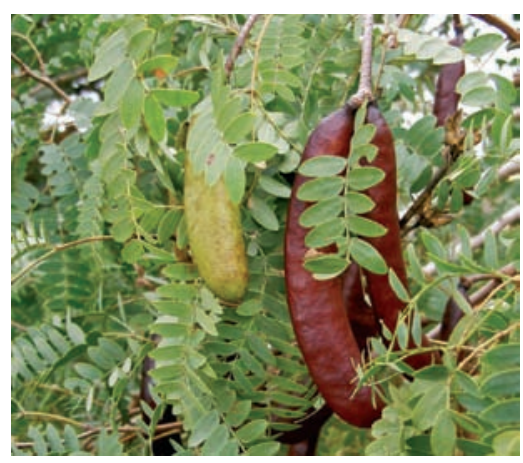

Prosopis africana 
III. Sección Strombocarpa. Árboles y arbustos con espinas foliares, estípulas lignificadas, rectas, en pares divergentes, tamaño variable. 9 especies.

Serie Strombocarpae. SW de USA y desde México hasta Chile. 7 especies
P. strombulifera (Lam.) Bentham
var. strombulifera
var. ruiziana Burkart
P. reptans Bentham
var. reptans
var. cinerascens (A. Gray) Bentham
P. abbreviata Bentham
P. torquata (Cavanilles ex Lagasca) DC.
$P$. pubescens Bentham
P. palmeri S.Watson
P. burkartii Muñoz

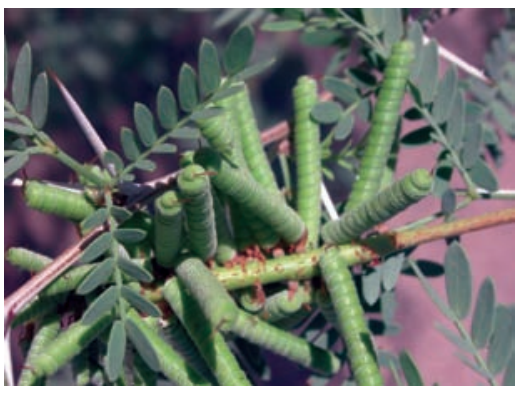

Serie Cavenicarpae. Sudamérica. 2 especies
P. ferox Grisebach
P. tamarugo F.Philippi

\section{Prosopis pubescens}

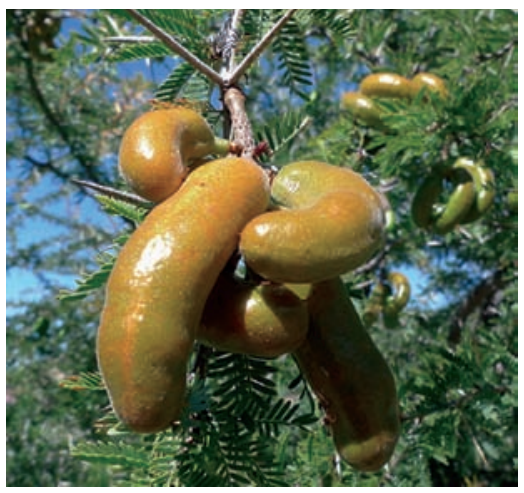

Prosopis ferox

IV. Sección Monilicarpa. Espinas axilares, solitarias, pequeñas. W de Argentina. 1 especie.

\section{P. argentina Burkart}

V. Sección Algarobia. Árboles, arbustos, raramente subarbustos, con espinas, raramenente sin ellas. Espinas caulinares, axilares uninodales, solitarias o frecuentemente en pares. Zonas más cálidas y secas de América. 29 especies.

Serie Sericanthae. Con espinas axilares y terminales. Argentina y Paraguay. 2 especies.

P. sericantha Gillies ex Hooker \& Arnott

P. kuntzei Harms

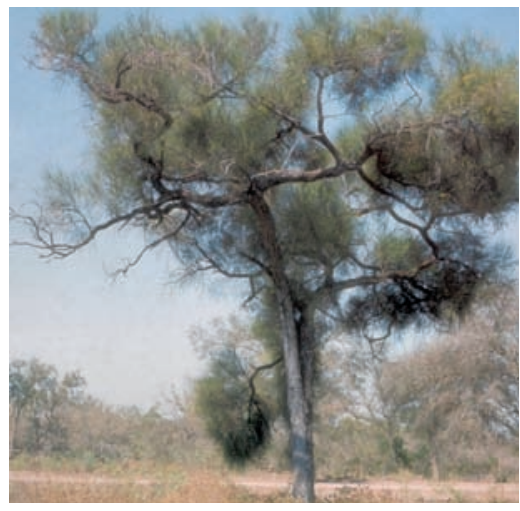

Prosopis kuntzei 
Serie Ruscifoliae. Con espinas axilares, uninodales, solitarias. Chaco Argentina y Paraguay. 4 especies.

P. ruscifolia Grisebach

P. fiebrigii Harms

P. vinalillo Stuckert

P. hassleri Harms

var. hassleri

var. nigroides Burkart

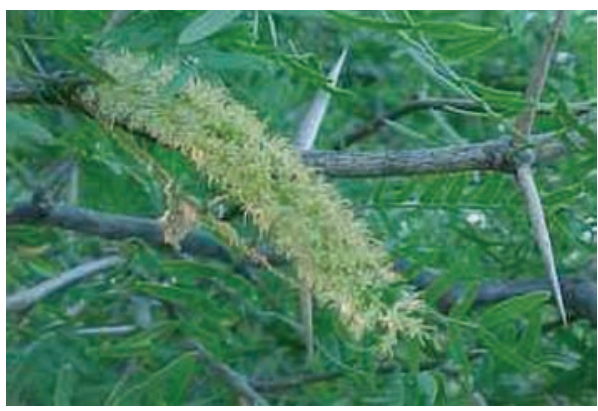

Prosopis vinalillo

Serie Denudantes. Espinas axilares, uninodales, siempre solitarias. SW de Argentina, Patagonia, Cuyo. 4 especies.

P. denudans Bentham

var. denudans

var. patagonica (Spegazzini) Burkart

var. stenocarpa Burkart

$P$. ruizleali Burkart

P. castellanosii Burkart

$P$. calingastana Burkart

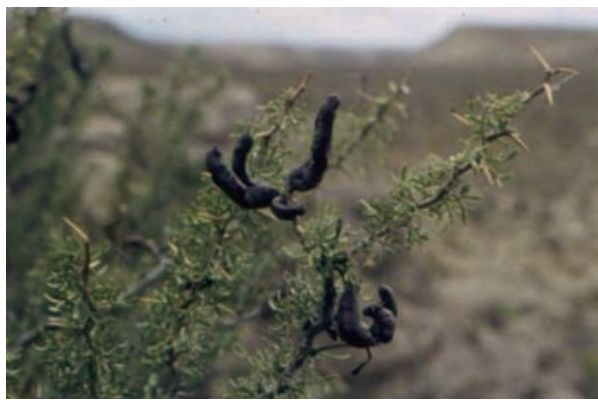

Prosopis denundans var. patagonica

Serie Humiles. Espinas axilares, uninodales. Centro de Argentina y Paraguay. 2 especies.

P. humilis Gillies ex Hooker \& Arnott

$P$. rojasiana Burkart

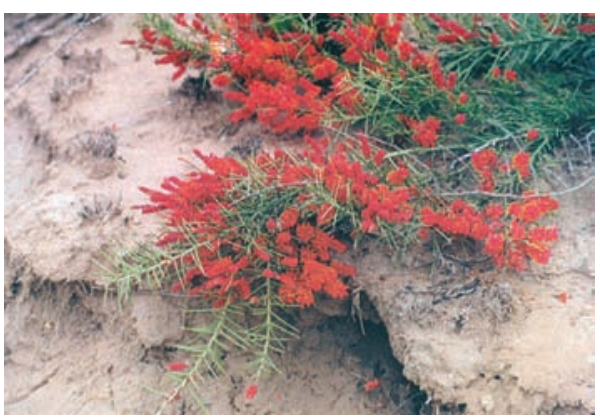

Prosopis humilis 
Serie Pallidae. Espinas axilares uninodales. México a Argentina. 7 especies.

P. rubriflora E. Hassler

P. campestris Grisebach

P. pallida (Humboldt \& Bonpland ex Willd.)

H.B.K.

$P$. affinis Sprengel

$P$. articulata S. Watson

P. elata (Burkart) Burkart

P. tamaulipana Burkart

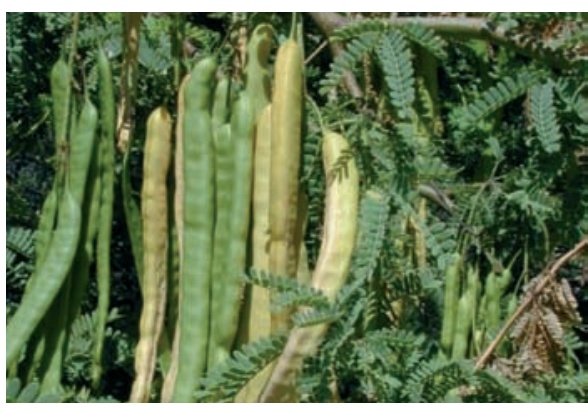

Prosopis pallida

Serie Chilenses. Espinas axilares uninodales, rara vez alternas. SW de USA y México hasta Chile, Argentina y uruguay. 11 especies.

P. chilensis (Molina) Stuntz emend. Burkart var. chilensis

var. riojana Burkart

var. catamarcana Burkart

P. juliflora Swartz DC.

var. juliflora

var. inermis (H.B.K.) Burkart

var. horrida (Kunth) Burkart

P. nigra (Grisebach) Hieronymus

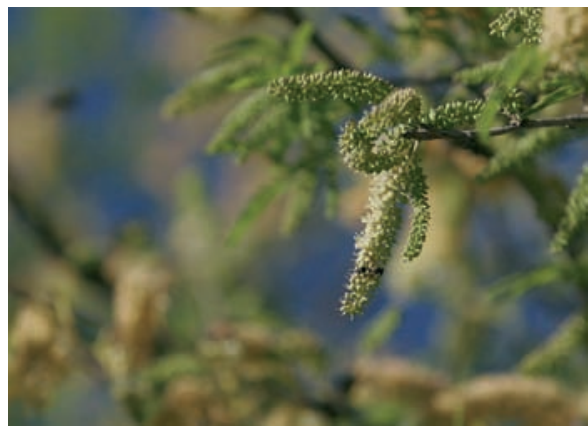

var. nigra

var. ragonesei Burkart

var. longispina Burkart

P. caldenia Burkart

P. laevigata (Humboldt \& Bonpland ex Willd.) M.C.Johnston

var. laevigata

var. andicola Burkart

P. flexuosa DC.

forma subinermis Burkart

P. glandulosa Torrey

var. glandulosa

var. torreyana (Benson) Johnston

var. prostrata Burkart

P. alpataco R.A.Philippi

P. alba Grisebach

var. alba

var. panta Grisebach

P. velutina Wooton

P. pugionata Burkart 


\section{Distribución Geográfica}

La distribución natural del género incluye las zonas áridas y semiáridas de América, África y Asia, este rango de dispersión natural puede ser en forma aproximada dividido en cinco regiones, identificadas simplemente como Asia, África, Norteamérica, Centroamérica y Sudamérica. Si bien hay cierto traslapo, cada una de estas regiones es geográficamente diferente (Pasiecznik et al 2001).

Las especies de Asia de la Sección Prosopis; P. cineraria, P. farcta y P. koelziana, son nativas del Medioeste, extendiéndose al este hacia India, al norte hacia Georgia y Turkmenistan y al oeste hacia Argelia a lo largo de la costa del norte de África.

Prosopis africana, la especie única de la Sección Anonychium, es nativa de la región de Sahel, desde Senegal en el oeste hasta Sudán y Kenya en el este. No hay sobreposición entre la distribución de Prosopis africana y la de las otras especies del Viejo Mundo.

Las restantes 40 especies, de las secciones Strombocarpa, Monilicarpa y, principalmente, Algarobia, son nativas de América donde se pueden definir tres áreas geográficas; Norte de México y USA, Argentina y países vecinos, y una zona central intermedia. Esta última está poblada principalmente por Prosopis juliflora y P. pallida, ocupando el norte de Sudamérica, el sur de Centroamérica y El Caribe. Sin embargo, los extremos norte y sur de esta zona intermedia no están bien definidos y puede existir cierta sobreposición con las otras dos áreas.

Latitudinalmente, las especies de Prosopis en América se distribuyen aproximadamente entre $37^{\circ} \mathrm{LN}$ en USA y $48^{\circ} \mathrm{LS}$ en Argentina.

Sin embargo, la influencia humana, a través de la introducción de especies más allá de sus áreas de distribución natural y de la deforestación por sobreuso, incendios y expansión de las fronteras agrícolas durante los últimos 500 años, sumada al agresivo comportamiento invasivo de algunas especies, han alterado significativamente la distribución global del género. En las Figuras $N^{\circ}$ s 4 y 5 se indica la distribución natural del género y la distribución actual, respectivamente. 


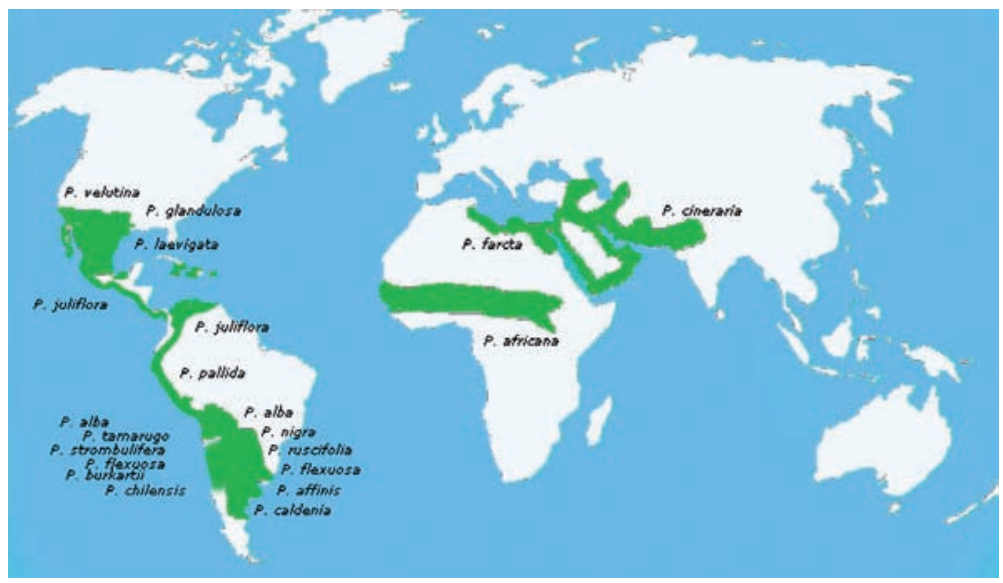

(Adaptado de Pasiecznik et al., 2001)

Figura $N^{\circ} 4$

DISTRIBUCIÓN NATURAL GÉNERO PROSOPIS Y PRINCIPALES ESPECIES

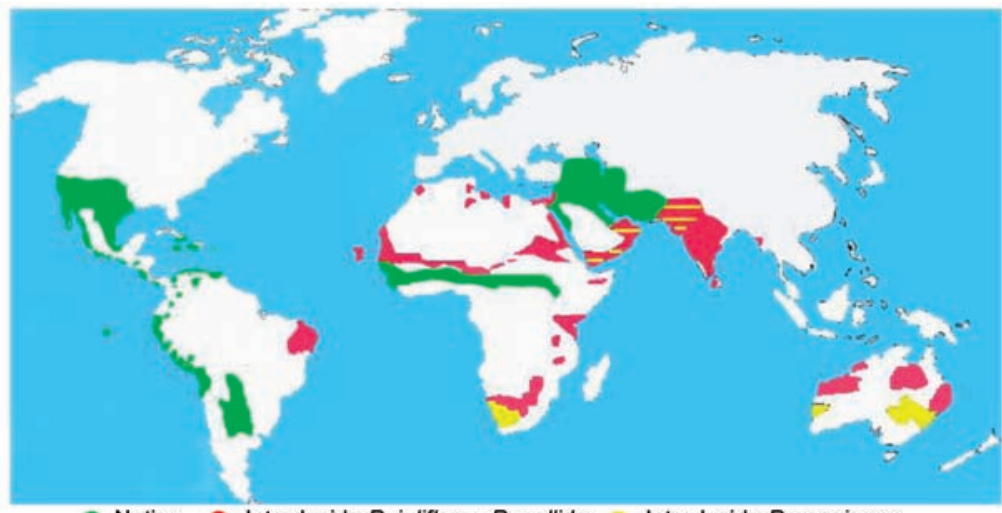

- Nativo Introducido P. juliflora-P. pallida Introducido Prosopis spp.

(Adaptado de Pasiecznik et al., 2001)

\section{DISTRIBUCIÓN ACTUAL GÉNERO PROSOPIS Y PRINCIPALES ESPECIES}

Las especies del género varían desde arbustos, de 1, 2 ó $3 \mathrm{~m}$ de altura, hasta árboles que pueden superar los $20 \mathrm{~m}$ de altura, la mayoría son resistentes a frio, a salinidad en el suelo y a sequía, y soportan también sucesivas cortas, Su madera es en general densa a muy densa y de elevado poder calorífico, lo que la hace interesante para productos madereros, en el caso de las especies mayores, y para combustible, como leña y carbón, en las menores. Proveen también de una variedad de productos no madereros, como alimento, forraje, mieles, taninos, tintes, ceras, gomas y compuestos medicinales. 
Estas características hacen de los algarrobos y mezquites especies muy interesantes, lo que ha llevado a su sobre utilización en sus áreas de origen, a su reintroducción en éstas via plantación y a su introducción fuera de sus regiones de distribución natural en distintos lugares del mundo. Esta última práctica tiene en muchas ocasiones muy buenos resultados, en términos de crear importantes recursos en nuevas áreas, pero en otras, dependiendo de las especies, de la evaluación del proceso de introducción y de las condiciones de sitio y el manejo en las zonas de destino, se puede obtener una diseminación descontrolada de algunas especies que tienen un agresivo hábito invasor.

Pasiecznik et al. (2001) resumen algunas características principales de las especies del género, destacando 21 de ellas que pueden lograr alturas máximas por sobre los $7 \mathrm{~m}$, descartando así las arbustivas menores (Cuadro $\mathrm{N}^{\circ} 1$ ).

\section{Cuadro $\mathrm{N}^{\circ} 1$}

\section{ALGUNAS CARACTERÍSTICAS DE LAS PRINCIPALES ESPECIES DEL GENERO PROSOPIS}

\begin{tabular}{|c|c|c|c|c|c|}
\hline Especie & $\begin{array}{l}\text { Altura } \\
\text { Máxima } \\
\text { (m) }\end{array}$ & $\begin{array}{c}\text { Espinas } \\
\text { (mm) }\end{array}$ & $\begin{array}{l}\text { Resistencia } \\
\text { Frio (1) } \\
\left({ }^{\circ} \mathrm{C}\right)\end{array}$ & $\begin{array}{c}\text { Resistencia } \\
\text { Salinidad }\end{array}$ & $\begin{array}{l}\text { Hábito } \\
\text { Invasor }\end{array}$ \\
\hline P. alba & 15 & 0 a 40 & $-5 a-15$ & $M$ & $M$ \\
\hline P. africana & 20 & - & -5 & $M$ & $\mathrm{~N}$ \\
\hline$P$. affinis & 8 & 3 a 25 & $-5 a-15$ & $M$ & $M$ \\
\hline P. caldenia & 12 & 5 a 25 & -15 & $\mathrm{~N}$ & A \\
\hline P. chilensis & 10 & 0 a 60 & -15 & A & A \\
\hline P. cineraria & 7 & 3 a 8 & -15 & A & $M$ \\
\hline P. flexuosa & 10 & 0 a 40 & $-5 a-15$ & $M$ & $M$ \\
\hline P. fiebrigii & 15 & 2 a 10 & $-5 a-15$ & $M$ & $\mathrm{~N}$ \\
\hline P. glandulosa & 9 & 10 a 45 & -15 & A & A \\
\hline P. hassleri & 10 & - & $-5 a-15$ & M & $\mathrm{N}$ \\
\hline P. juliflora & 12 & 0 a 50 & -5 & A & A \\
\hline P. kuntzei & 10 & 80 a 500 & $-5 a-15$ & $M$ & $M$ \\
\hline P. laevigata & 7 & 5 a 25 & -15 & A & $M$ \\
\hline$P$. nigra & 10 & 0 a 35 & $-5 a-15$ & A & $M$ \\
\hline P. pallida & 20 & 0 a 40 & -5 & A & A \\
\hline P. pubescens & 10 & 2 a 20 & -15 & $M$ & $M$ \\
\hline P. pugionata & 8 & 20 a 95 & $-5 a-15$ & $M$ & $M$ \\
\hline P. nuscifolia & 12 & 10 a 330 & $-5 a-15$ & A & A \\
\hline P. tamanugo & 18 & 5 a 38 & $-5 a-15$ & A & $\mathrm{N}$ \\
\hline$P$. velutina & 15 & 10 a 20 & -15 & $M$ & A \\
\hline$P$. vinalillo & 10 & 5 a 120 & $-5 a-15$ & $M$ & $M$ \\
\hline \multicolumn{6}{|c|}{$\begin{array}{l}\text { N: No M Moderado A: Alto } \\
\text { (1): Rangos aproximados, pero depende de la temperatura minima absoluta, la duración de esta minima } \\
\text { y el tiempo bajo } 0{ }^{\circ} \mathrm{C} \text {. }\end{array}$} \\
\hline
\end{tabular}




\section{- Deforestación}

Información de la Organización de las Naciones Unidas para la Agricultura y la Alimentación (FAO, 2010) señala que la cubierta forestal mundial es de algo más de 4 mil millones de hectáreas, pero que el mundo pierde anualmente 13 millones de hectáreas de bosques, principalmente por el avance de las fronteras agrícolas sobre bosques tropicales, pero también debido a incendios y a sobre explotación. Esta preocupante cifra corresponde al decenio 2000 - 2010, sin embargo los países están desplegando esfuerzos para reducir la deforestación, durante la década anterior la tasa de pérdida de bosques era de 16 millones de hectáreas.

Por su parte las plantaciones forestales a gran escala han aumentado, reduciendo las pérdidas netas globales de cubierta forestal, que en el período 1990-2000 eran de 8,2 millones de hectáreas anuales y en el decenio siguiente 2000-2010 bajan significativamente a 5,3 millones de hectáreas por año.

Las formaciones boscosas de especies del género Prosopis no han sido la excepción en los procesos de deforestación en el mundo, tanto en América del Norte como en Sudamérica han sido desplazadas por cultivos agrícolas, han sido intensamente explotadas para madera, combustible y otros productos, y han sufrido selección genética negativa (disgenia) producto del "floreo" (explotación de los mejores ejemplares).

Se estima que en Argentina las formaciones naturales originales de Prosopis se han reducido por acción antrópica entre un 50 y un 75\% desde el año 1500 (D'Antoni and Solbrig 1977. Cit. por Pasiecznik et al., 2001). En Äfrica, los Prosopis nativos ya raramente se pueden encontrar en rodales puros y en los ecosistemas de sabana, de los que forman parte, se han extendido las tierras desérticas de norte a sur, en tanto de sur a norte existe una permanente presión ejercida por las actividades agrícolas y ganaderas, incrementada por el interés por la madera y combustible que los bosques pueden entregar. Adicionalmente, la extracción de agua por el hombre ha provocado el descenso de las napas freáticas conduciendo a la muerte de los bosques en zonas del centro de África. En Asia también se registran pérdidas de formaciones naturales de Prosopis, debidas principalmente a la demanda por combustible (ICFRE, 1993; von Maydell, 1986. Cit. por Pasiecznik et al., 2001).

\section{- Introducción de Especies}

La introducción de especies, mediante plantaciones fuera de sus regiones de distribución natural con el objeto de crear recursos productivos, proteger suelos o simplemente con fines ornamentales, ha sido una práctica histórica del ser humano. En sus inicios el desplazamiento de las especies era accidental, como resultado de semillas que transportaban pueblos trashumantes, pero posteriormente la introducción de especies fue intencionada siguiendo objetivos definidos y para satisfacer necesidades específicas.

Como ya se comentó en puntos anteriores, en el caso de África se han introducido especies de Prosopis en 25 países, abarcando todas las regiones del continente (Pasiecznik et al., 2001), y algo semejante ha ocurrido en Asia, Islas de Hawaii, islas Marquesas, Filipinas y 
Australia, además de plantaciones con especies nativas en América, como el caso de Prosopis tamarugo, P. alba y P. chilensis, en el norte de Chile (Burkart, 1976).

La mayoría de las introducciones de especies del género se han efectuado con Prosopis juliflora, P. pallida, P. glandulosa y $P$. velutina, las dos primeras en zonas tropicales y las dos últimas en zonas subtropicales. Prosopis alba y $P$. chilensis han mostrado buena adaptación en diferentes regiones, en tanto que especies como Prosopis cineraria, $P$. pubescens y $P$. tamarugo han sido ampliamente introducidas en diferentes regiones con negativos resultados, raramente sobreviven.

\section{- Especies Invasoras}

Como ya se ha mencionado, varias especies del género pueden ser invasivas y algunas de ellas son agresivamente invasoras bajo condiciones favorables para su diseminación.

Algunas especies muestran un comportamiento invasivo en sus zonas de origen, colonizando zonas alteradas por incendios, sobre explotación u otras causas, aspecto que debió tomarse en consideración antes de introducirlas en otras áreas. Es el caso de las cuatro especies del género con las cuales se han realizado la mayoría de las introducciones.

Pasiecznik et al. (2001) indican las principales especies invasoras en sus regiones de origen y en las de introducción (Cuadro $N^{\circ} 2$ ). Las cuatro especies más difundidas se han transformado en malezas en algunas zonas en donde han sido introducidas.

La gran cantidad de semillas que producen, su capacidad para resistir prolongados períodos secos, sus raíces pivotantes que pueden alcanzar napas subterráneas a más de 10 $\mathrm{m}$ de profundidad en algunos casos y su potencial de recuperación después de sucesivas cortas, permiten a estas especies, si no se las maneja, avanzar sobre terrenos despejados por incendios y explotación de bosques naturales o deforestados para uso agrícola y ganadero, constituyendo densas formaciones espinosas, que impiden el desarrollo de pastos y el ingreso de ganado, y que resultan muy difíciles de controlar o erradicar.

Es así como varias especies del género están hoy incorporadas en las listas de malezas invasoras indeseables en diferentes países del mundo, como Australia, Argentina, USA, Kenya, Etiopía, Sudán y otros. 


\section{Cuadro $\mathrm{N}^{\circ} 2$ \\ ESPECIES DEL GÉNERO PROSOPIS QUE MUESTRAN HÁBITO INVASOR EN SUS REGIONES DE ORIGEN Y EN REGIONES EN QUE SE LAS HA INTRODUCIDO}

\begin{tabular}{|l|l|l|}
\hline Especie & Regiones de Origen & Regiones de Introducción \\
\hline & & \\
P. affinis & Argentina, Uruguay & \\
P. caldenia & Argentina & \\
P. campestris & Paraguay & \\
P. cineraria & Pakistán & \\
P. farcta & Israel, Jordan, Syria, Arabia, Irán, Turquia & \\
P. glandulosa & USA, México & Australia, Sudáfrica, Namibia \\
\cline { 2 - 2 } P. hassleri & Argentina & \\
P. humilis & Argentina & \\
P. kuntzei & Argentina & Sudan, Eritrea, Iraq, Pakistan, India, Australia, Sudäfrica, Islas del Caribe y del Atlántico \\
P. juliflora & Venezuela, Colombia & \\
P. nigra & Argentina & Australia, Hawai \\
P. pallida & USA & \\
P. pubescens & Argentina, Paraguay & \\
P. nuscifolia & USA & Australia, Sudáfrica \\
\hline P. velutina & \\
\hline Fuente: Pasiecznik et al., 2001) & \\
\hline
\end{tabular}

\section{EL GÉNERO PROSOPIS EN CHILE}

Chile presenta una extensa zona árida desértica en el norte, Regiones de Arica a Atacama, donde solo es posible la vida vegetal en zonas de valles transversales, en sectores en los que hay napas subterráneas relativamente cercanas a la superficie y en áreas de precordillera andina y altiplano.

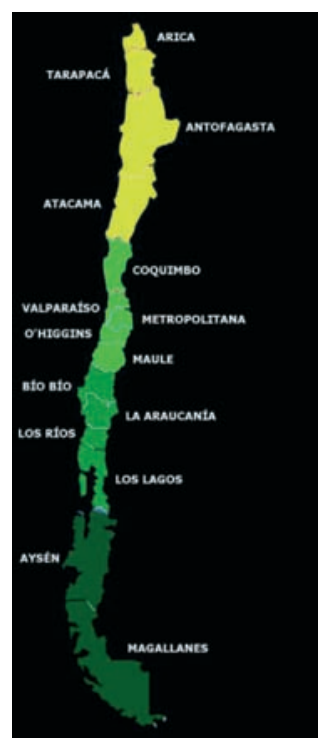

Figura $\mathrm{N}^{\circ} 6$

REGIONES DE CHILE 
Hacia el sur se encuentra una zona semiárida, que ocupa las Regiones de Coquimbo a Maule, en donde las precipitaciones anuales varían aproximadamente de $80 \mathrm{~mm}$ en el norte a algo más de $700 \mathrm{~mm}$ en el sur, fuertemente concentradas en invierno y con un período seco que oscila entre 8 y 5 meses. Más al sur las precipitaciones aumentan a través de una zona templada lluviosa y en el extremo sur las condiciones son de clima templado frío y semiárido.

\section{Especies}

Las especies del género Prosopis ocurren naturalmente en el país en las zonas áridas y semiáridas y están presentes desde la Región de Arica hasta la Región Metropolitana. En la zona árida prosperan solo asociadas a valles o a sectores con napa freática alta.

En Chile se encuentran seis especies del género; Prosopis chilensis, $P$. flexuosa, $P$. alba, P. strombulifera, P. tamarugo y P. burkartii, todas ellas nativas y las dos últimas endémicas (Burkart, 1976; Muñóz, 1971 Cit. por Barros y Wrann, 1992).

La Enciclopedia de la Flora Chilena (en línea) y Muñóz (1971, cit por Barros y Wrann, 1992 ) incluyen entre las especies nativas en Chile a Prosopis alpataco, sin embargo Burkart (1976) indica que corresponde a Prosopis flexuosa.

Tres de las especies corresponden a la Sección Strombocarpa y las tres restantes a la Sección Algarobia, una especie endémica en cada Sección.

\section{Sección Strombocarpa}

\section{Serie Strombocarpae}

\section{- Prosopis strombulifera var. strombulifera "Retortón"}

Arbusto espinoso de 0,15 a 1,5 m de altura, follaje pequeño, ramas flexibles, estípulas espinosas rectas de 0,1 a $2 \mathrm{~cm}$ de largo, pinas de 1 a $3 \mathrm{~cm}$ con 3 a 8 pares de folíolos alternos a opuestos de 2 a $9 \mathrm{~mm}$ de largo y 0,8 a $2 \mathrm{~mm}$ de ancho. Frutos color amarillo limón cuando maduros, 1,8 a 5,2 cm de largo por 0,6 a $1 \mathrm{~cm}$ de diámetro, espiralados. Semillas ovaladas de 4,5 a 5,4 mm de largo, verde grisáceas (Burkart, 1976).

Distribución natural: $\mathrm{W}$ de Argentina, $\mathrm{N}$ de Chile y $\mathrm{S}$ de Perú. 
Distribución natural en Chile: Regiones de Arica a Coquimbo
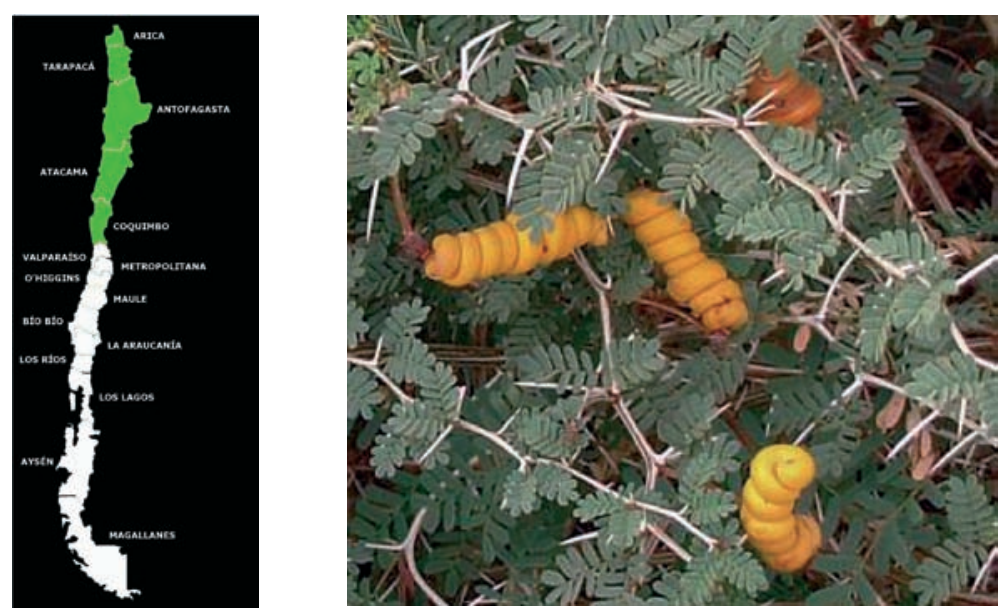

\section{- Prosopis burkartii}

Arbusto rastrero de 0,5 a $1,5 \mathrm{~m}$ de altura, con largas, densas e intricadas ramas, estípulas espinosas de 0,5 a $3 \mathrm{~cm}$ de largo. Pinas de $2 \mathrm{~cm}$ de largo con 7 a 12 pares de folíolos elípticos, oblongos, de 4 a $7 \mathrm{~mm}$ de largo por 1 a $2 \mathrm{~mm}$ de ancho. Legumbres espiraladas, 2 a 3 espirales, color café. Semillas de 5,2 mm de largo por $4 \mathrm{~mm}$ de ancho (Burkart, 1976).

Distribución natural: $\mathrm{N}$ de Chile. Pampa del tamarugal. Especie endémica.
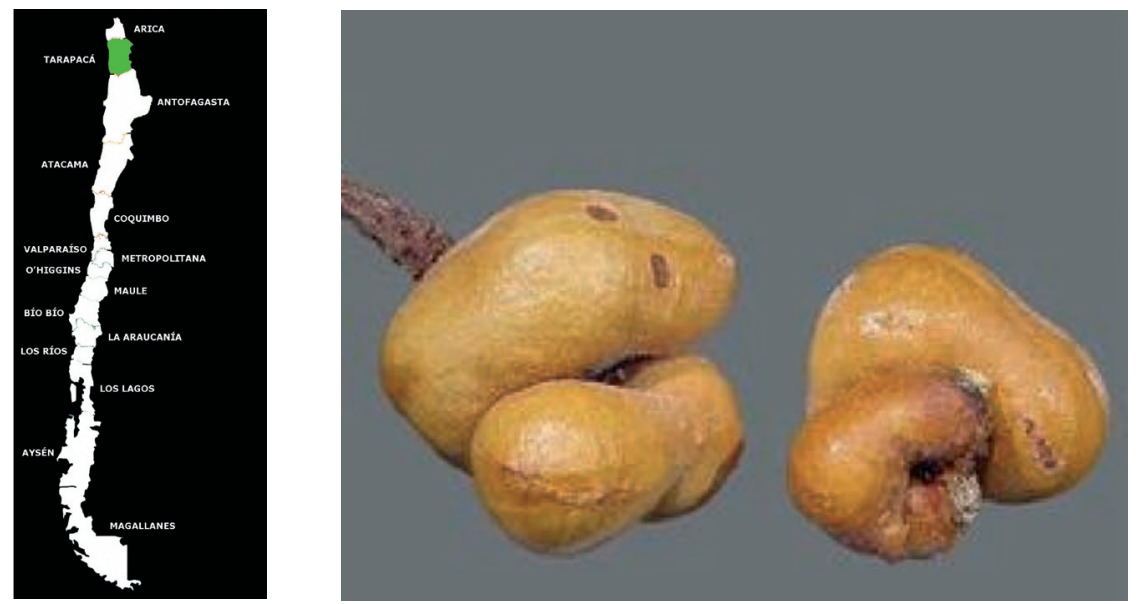


\section{Serie Cavenicarpae.}

\section{- Prosopis tamarugo "Tamarugo"}

Árbol de hasta $18 \mathrm{~m}$ de altura, estípulas espinosas de 0,5 a 3,8 $\mathrm{cm}$ de largo, pinas de 3 a $4 \mathrm{~cm}$ con 10 a 15 pares de folíolos lineales, obtusos de 4 a $8 \mathrm{~mm}$ de largo. Legumbres amarillo paja o café claro, anulares, 2 a $3,5 \mathrm{~cm}$ de diámetro o menos y 7 a $10 \mathrm{~mm}$ de espesor. Semillas ovales, color café, de 3 a 4,3 mm de largo (Burkart, 1976).

Distribución natural: Chile. Pampa del Tamarugal Región de Tarapacá, sectores del sur de la Región de Arica y del interior de la Región de Antofagasta. Especie endémica.
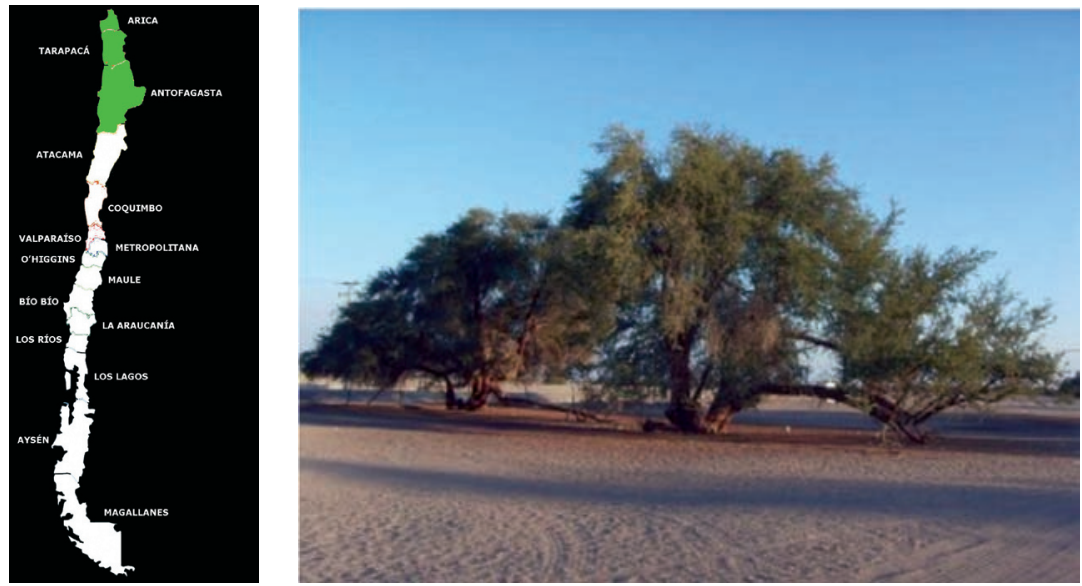

\section{Sección Algarobia.}

\section{Serie Chilenses.}

\section{- Prosopis chilensis var. chilensis "Algarrobo Chile no"}

Árbol de tronco corto, 3 a $10 \mathrm{~m}$, puede alcanzar 14 a $15 \mathrm{~m}$ altura total y diámetros de más de $1 \mathrm{~m}$. Copa redonda, ramas flexibles, nudosas, parcialmente espinosas, espinas fuertes, axilares, uninodales, de hasta $6 \mathrm{~cm}$. Hojas deciduas o semi deciduas, pinas de 8 a $24 \mathrm{~cm}$ de largo con 10 a 19 pares de folíolos largos de 1,1 a 5,4 cm de largo por 1,1 a 3 $\mathrm{cm}$ de ancho, color verde pálido. Legumbres amarillas, lineares de 12 a $18 \mathrm{~cm}$ de largo, 1 a $1,8 \mathrm{~cm}$ de ancho y $0,6 \mathrm{~cm}$ espesor. Semillas ovoides, color café, 6 a $7 \mathrm{~mm}$ largo.

Distribución natural: Desde Perú y Bolivia a Chile central y NW de Argentina. 
Distribución natural en Chile: Regiones de Atacama a Metropolitana.
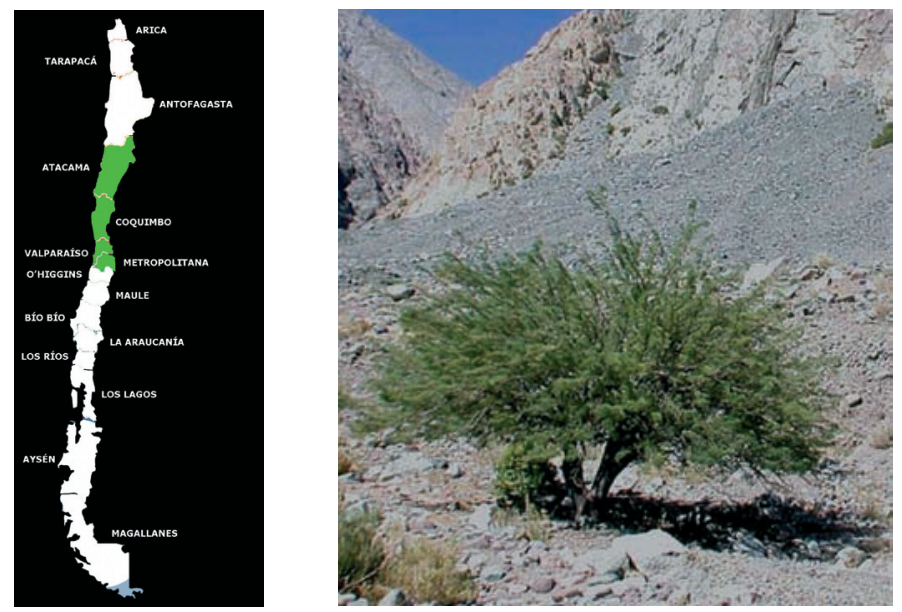

\section{- Prosopis flexuosa "Algarrobo"}

Árbol o arbusto erecto ramificado, 3 a 10 m de altura, copa hemisférica con extremos de ramas péndulos, flexibles y nudosos. Espinas axilares, comúnmente pequeñas o ausentes, a veces fuertes de 3 a $4 \mathrm{~cm}$ de largo. Follaje claro, deciduo, abundante, pinas de 5 a $13 \mathrm{~cm}$ de largo, 12 a 29 pares de folíolos lineares, 4 a $15 \mathrm{~mm}$ por 1 a $2 \mathrm{~mm}$. Legumbre casi recta, 5 a $28 \mathrm{~cm}$ de largo por 0,7 a 1,2 cm de ancho, con tintes violeta hasta negro violáceo.

Distribución natural: $\mathrm{N}$ de Chile y W de Argentina
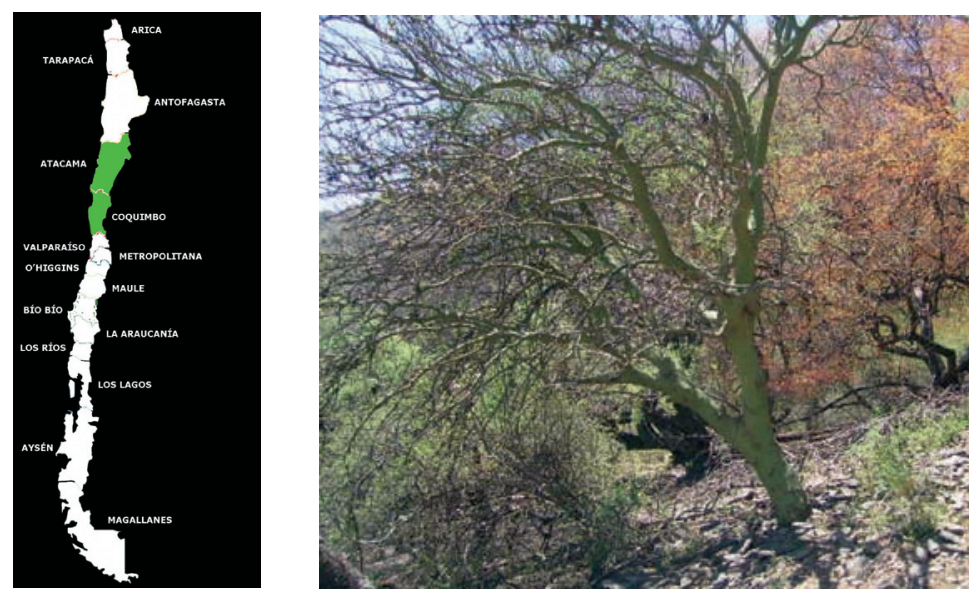
Distribución natural en Chile: Regiones de Atacama y Coquimbo.

\section{- Prosopis alba var panta "Algarrobo"}

Árbol de 5 a $15 \mathrm{~m}$ de altura, tronco corto, en estado adulto puede alcanzar $1 \mathrm{~m}$ de diámetro. Copa redondeada, ramas colgantes, espinas escasas y pequeñas, 2 a $4 \mathrm{~cm}$ de largo. Pinas de 6 a $4 \mathrm{~cm}$ de largo, con 25 a 50 pares de folíolos lineares de 0,5 a 1,7 $\mathrm{cm}$ de largo por 1 a $2 \mathrm{~mm}$ de ancho. Legumbre de forma falcada a anular, amarilla, $12 \mathrm{a}$ $25 \mathrm{~cm}$ de largo, 11 a $20 \mathrm{~mm}$ ancho y 4 a $5 \mathrm{~mm}$ espesor (Burkart, 1976).

Distribución natural: Planos de Argentina subtropical a Uruguay, Paraguay, sur de Bolivia, Perú y norte de Chile.

Distribución natural en Chile: Regiones de Arica, Tarapacá y Antofagasta.
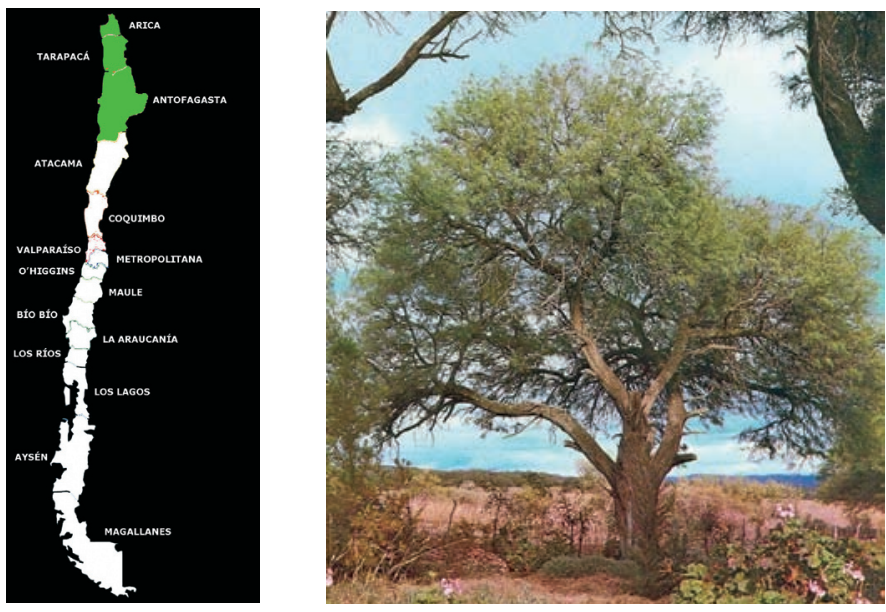

\section{Superficie y Distribución de las Formaciones de Prosopis en Chile}

Entre las Regiones de Arica y Metropolitana existen formaciones naturales y plantaciones forestales con especies del género. Barros y Wrann (1992), basados en trabajos de INFOR $(1981 ; 1986)$ señalan que en el país hay un total de 50.439 ha de formaciones de Prosopis spp las cuales se distribuyen según región y tipo de bosque, como indica el Cuadro $\mathrm{N}^{\circ} 3$. 


\section{Cuadro $\mathrm{N}^{\circ} 3$ \\ SUPERFICIE FORMACIONES DE PROSOPIS \\ (1986)}

\begin{tabular}{|l|r|r|r|}
\hline \multirow{2}{*}{ Región } & \multicolumn{3}{|c|}{ Superficie } \\
\cline { 2 - 4 } & \multicolumn{1}{|c|}{ Natural } & \multicolumn{1}{|c|}{ Plantado } & \multicolumn{1}{|c|}{ Total } \\
\cline { 2 - 4 } & \multicolumn{3}{|c|}{ (ha) } \\
Tarapacá & 3.465 & 23.153 & 26.618 \\
Antofagasta & 2.074 & 880 & 2.954 \\
Atacama & 766 & 10 & 767 \\
Coquimbo & 6.656 & & 6.666 \\
Valparaíso & 1.616 & & 1.615 \\
Metropolitana & 11.819 & & 11.819 \\
& & & \\
\hline Total & 26.396 & & $\mathbf{2 4 . 0 4 3}$ \\
\hline
\end{tabular}

(Fuente: Barros y Wrann, 1992)

INFOR (2009), entrega cifras más recientes (2008) para plantaciones de tamarugo y algarrobo, en las mismas regiones, que elevan la superficie total para este tipo de bosques a 25.799 ha y, consecuentemente, el total de Prosopis a 52.195 ha (Cuadro N 4).

La diferencia corresponde a nuevas plantaciones realizadas en la Región de Tarapacá, a pérdidas probablemente por escasa supervivencia en plantaciones de la Región de Antofagasta y a plantaciones de algarrobo que anualmente se están estableciendo en la Región de Coquimbo.

\section{Cuadro $\mathrm{N}^{\circ} 4$ \\ PLANTACIONES DE PROSOPIS \\ (2008)}

\begin{tabular}{|l|r|}
\hline Región & \multicolumn{1}{|c|}{$\begin{array}{c}\text { Superficie } \\
\text { (ha) }\end{array}$} \\
\hline Tarapacá & 23.881 \\
Antofagasta & 349 \\
Atacama & 425 \\
Coquimbo & 1.139 \\
Valparaíso & 5 \\
Metropolitana & 25.799 \\
\hline
\end{tabular}

(Fuente: INFOR, 2009) 
INFOR (2009) entrega también superficies actualizadas de bosques naturales para estas regiones, por un total superior a 200.000 ha, sin embargo están agrupadas por Tipo Forestal, en este caso Esclerófilo, que sólo en el caso de la Región de Tarapacá coincide con formaciones de Prosopis spp, hacia el sur, y en especial de Coquimbo al sur, se incorporan mayoritariamente otras especies en el tipo y las especies del género participan minoritariamente o no lo hacen.

Las especies que componen tanto los bosques naturales como los plantados son Prosopis tamarugo, $P$. alba y $P$. chilensis, las tres restantes; Prosopis burkartii, $P$. strombulifera y $P$. flexuosa, tienen presencia en sus áreas de distribución natural antes indicadas, pero no significación en las cifras de superficies.

Tomando las cifras de bosque natural del Cuadro $N^{\circ} 3$ (INFOR, 1986) y las de bosques plantados del Cuadro N ${ }^{\circ} 4$ (INFOR, 2008), cifras de detalle por región (Barros y Wrann, 1992) y teniendo presente que la antigua I Región corresponde a lo que hoy son las Regiones de Arica y Tarapacá, se puede hacer una estimación muy general de la superficie de bosques naturales y plantados, por especie y región (Cuadro $\mathrm{N}^{\circ} 5$ ).

\section{Cuadro $\mathrm{N}^{\circ} 5$}

\section{SUPERFICIE BOSQUES NATURALES Y PLANTACIONES DE PROSOPIS SEGÚN REGIÓN Y} ESPECIE

\begin{tabular}{|c|c|c|c|c|c|c|c|c|c|}
\hline \multirow{3}{*}{ Región } & \multicolumn{4}{|c|}{ Natural } & \multicolumn{4}{|c|}{ Plantado } & \multirow{3}{*}{$\begin{array}{l}\text { Total } \\
\text { (ha) }\end{array}$} \\
\hline & \multicolumn{8}{|c|}{ (ha) } & \\
\hline & P. tamarugo & P. alba & P. chilensis & Sub Total & P. tamarugo & P. alba & P. chilensis & Sub Total & \\
\hline Tarapacá & 3.295 & 113 & & 3.407 & 20.635 & 3.246 & & 23.881 & 27.288 \\
\hline Antofagasta & & 2.075 & & 2.075 & 47 & 302 & & 349 & 2.424 \\
\hline Atacama & & & 767 & 767 & 12 & & 413 & 425 & 1.192 \\
\hline Coquimbo & & & 6.656 & 6.656 & & & 1.139 & 1.139 & 7.795 \\
\hline Valparalso & & & 1.616 & 1.616 & & & & & 1.616 \\
\hline Metropolitana & & & 11.819 & 11.819 & & & 5 & 5 & 11.824 \\
\hline Total & 3.295 & 2.187 & 20.857 & 26.339 & 20.694 & 3.548 & 1.557 & 25.799 & 52.138 \\
\hline
\end{tabular}

Del Cuadro $\mathrm{N}^{\circ} 5$ se desprende que la superficie total por especie es la que se indica en el Cuadro $\mathrm{N}^{\circ} 6$. 


\section{Cuadro $N^{\circ} 6$ SUPERFICIE POR ESPECIE}

\begin{tabular}{|c|c|c|c|c|}
\hline \multirow{3}{*}{ Región / Comuna } & \multicolumn{4}{|c|}{ Superficie por Especie } \\
\hline & \multicolumn{4}{|c|}{ (ha) } \\
\hline & P. tamarugo & P. alba & P. chilensis & Total \\
\hline Tarapacá & 23.929 & 3.359 & & 27.288 \\
\hline Antofagasta & 47 & 2.377 & & 2.424 \\
\hline Atacama & 12 & & 1.180 & 1.192 \\
\hline Coquimbo & & & 7.795 & 7.795 \\
\hline Valparaíso & & & 1.616 & 1.616 \\
\hline Metropolitana & & & 11.823 & 11.823 \\
\hline Total & 23.988 & 5.736 & 22.414 & 52.138 \\
\hline
\end{tabular}

Barros y Wrann (1992), sobre la base de información de INFOR (1981; 1986), señalan que Prosopis tamarugo está casi en su totalidad en la Región de Tarapacá, tanto en formaciones naturales como plantaciones, en las Comunas de Pozo Almonte y Huara.

Las principales concentraciones de bosques de Prosopis alba en el país están representadas por plantaciones en la Comuna de Pozo Almonte, Región de Tarapacá, y formaciones naturales en la Comuna de San Pedro de Atacama, Región de Antofagasta.

Prosopis chilensis por su parte, con una distribución más amplia, muestra sus mayores expresiones en la Comunas de Alto del Carmen, Región de Atacama; Monte Patria y Combarbalá, Región de Coquimbo; Calle Larga, Región de Valparaíso; y Til Til y Colina, en la Región Metropolitana. Todo esto representado por bosques naturales, sólo en la Región de Coquimbo hay plantaciones de significación en términos de superficie (Cuadro $\mathrm{N}^{\circ} 7$ ). 


\section{Cuadro $\mathrm{N}^{\circ} 7$ \\ PRINCIPALES CONCENTRACIONES DE FORMACIONES DE PROSOPIS EN CHILE}

\begin{tabular}{|c|c|c|c|c|}
\hline \multirow{3}{*}{ Región / Comuna } & \multicolumn{4}{|c|}{ Principales Concentraciones de Prosopis } \\
\hline & \multicolumn{4}{|c|}{ (ha) } \\
\hline & P. tamarugo & P. alba & P. chilensis & Total \\
\hline Tarapacá & 22.860 & 3.136 & & 25.996 \\
\hline Huara & 4.312 & & & 4.312 \\
\hline Pozo Almonte & 18.547 & 3.136 & & 21.684 \\
\hline Antofagasta & & 1.890 & & 1.890 \\
\hline Maria Elena & & 296 & & 296 \\
\hline San Pedro de Atacama & & 1.594 & & 1.594 \\
\hline Atacama & & & 652 & 652 \\
\hline Copiapó & & & 100 & 100 \\
\hline Vallenar & & & 121 & 121 \\
\hline Alto del Carmen & & & 431 & 431 \\
\hline Coquimbo & & & 5.270 & 5.270 \\
\hline Vicuña & & & 1.168 & 1.168 \\
\hline Monte Patria & & & 1.939 & 1.939 \\
\hline Combarbalá & & & 2.061 & 2.061 \\
\hline Illapel & & & 101 & 101 \\
\hline Valparaiso & & & 2.014 & 2.014 \\
\hline San Felipe & & & 310 & 310 \\
\hline Calle Larga & & & 1.229 & 1.229 \\
\hline Llay Llay & & & 475 & 475 \\
\hline Metropolitana & & & 11.117 & 11.117 \\
\hline TII Til & & & 4.531 & 4.531 \\
\hline Colina & & & 6.585 & 6.585 \\
\hline Total & 22.860 & 5.026 & 19.052 & 46.938 \\
\hline
\end{tabular}

Las 16 comunas administrativas mencionadas en el Cuadro $\mathrm{N}^{\circ} 7$ reúnen algo más del $90 \%$ de la superficie de formaciones de Prosopis del país y sobre el $85 \%$ de las superficies totales por especie.

Las Comunas de Huara y Pozo Almonte, en la Región de Tarapacá, concentran el 50 \% de las formaciones de Prosopis del país, 29.996 ha, y el 95,3 \% de los bosques de tamarugo, 22.860 ha. La Comuna de Pozo Almonte sostiene el 54,7 \% de los bosques de Prosopis alba. Las formaciones naturales de Prosopis chilensis en tanto, se encuentran mayoritariamente en la Región Metropolitana, casi el 50 \%, 11.117 ha.

El las Comunas de Huara y Pozo Almonte, Región de Tarapacá, se encuentra la Pampa del Tamarugal y una gran parte de las formaciones de Prosopis en ella existentes está dentro de la Reserva Nacional Pampa del Tamarugal, unidad del Sistema Nacional de Áreas Silvestres Protegidas por el Estado (SNASPE) administrada por la Corporación Nacional Forestal (CONAF). Esta Reserva Nacional fue creada en el año 1987 y tiene una superficie total cercana a las 108.000 ha (CONAF, 1997) (Figura $N^{\circ} 7$ ). 

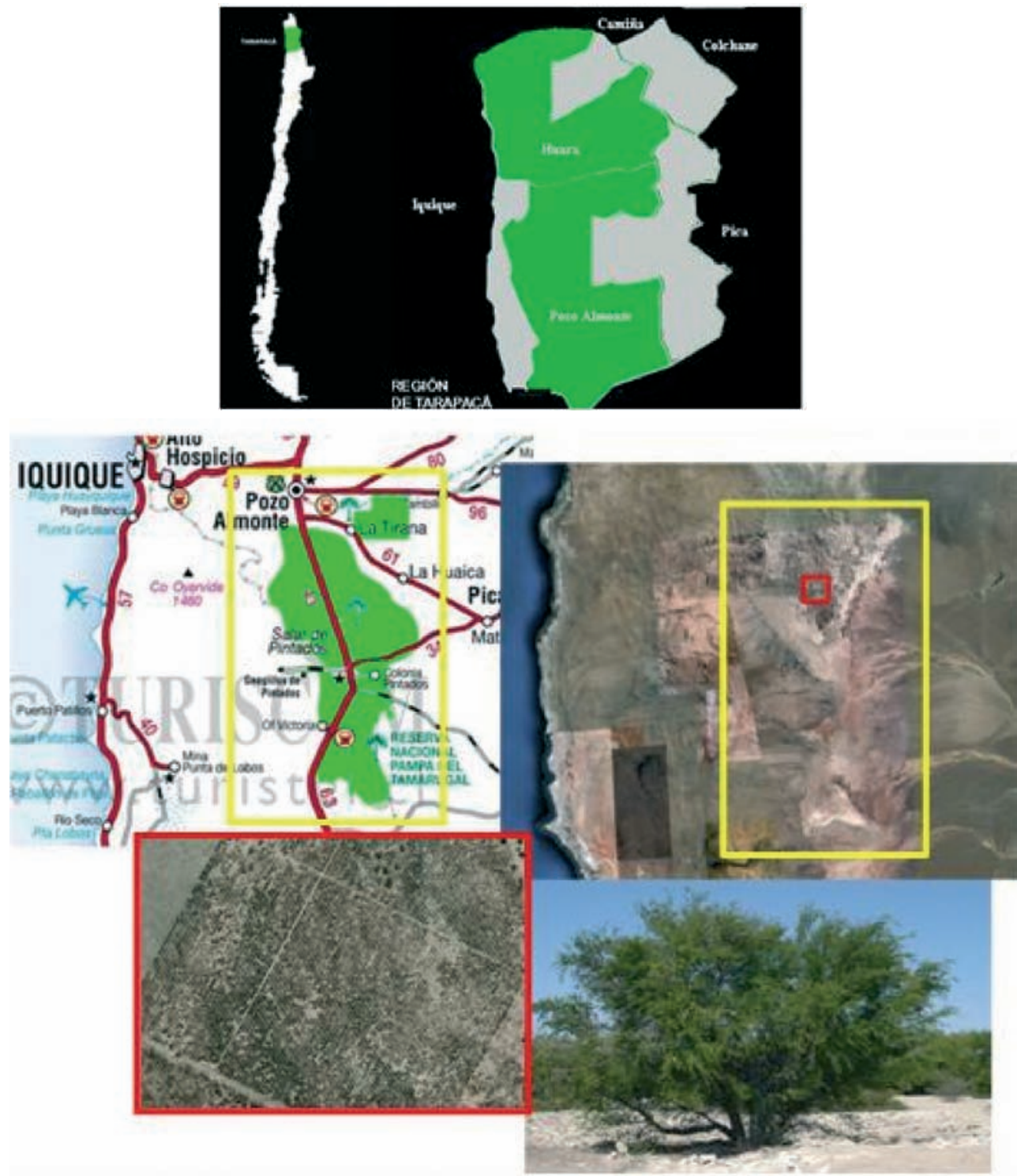

Figura $N^{\circ} 7$

RESERVA FORESTAL PAMPA DEL TAMARUGAL, COMUNAS DE HUARA Y POZO

ALMONTE

REGIÓN DE TARAPACÁ 
La Pampa del Tamarugal corresponde a una planicie ubicada en la Depresión Intermedia de la Región de Tarapacá, entre la Cordillera de Los Andes y la Cordillera de la Costa, desde los $19^{\circ} 33^{\prime} \mathrm{LS}$ a los $21^{\circ} 50^{\prime} \mathrm{LS}$, a una altitud media de $1.200 \mathrm{msnm}$ y con una pendiente media de $2 \%$ de $\mathrm{E}$ a W (CONAF, 1997).

El clima en la Pampa del Tamarugal, de acuerdo a Köppen (1900), corresponde al tipo desértico (BW), aún cuando no corresponde a un desierto cálido debido a que la altitud de esta pampa interior actúa como un regulador de las temperaturas, cosa que se aprecia en temperaturas medias mensuales de los meses más cálidos en torno a $21^{\circ} \mathrm{C}$, con un marcada amplitud de oscilación diaria. Las temperaturas extremas absolutas se mueven entre $-12^{\circ} \mathrm{C}$ en los meses más fríos y $36^{\circ} \mathrm{C}$ en los más cálidos. El promedio de días despejados por año es 250. La humedad relativa es baja en el día, 10 a $30 \%$, pero en la noche puede subir a $90 \%$

(niebla o "camanchaca"). Prácticamente no se registran precipitaciones.

La vegetación corresponde a Desierto del Tamarugal (Gajardo, 1994, Cit. por CONAF, 1997) y se distribuye en áreas donde la napa freática es relativamente superficial o reciben aluviones originados en la Cordillera de Los Andes por precipitaciones de verano ("invierno altiplánico"). Esta formación está constituida principalmente por Prosopis tamarugo y P. alba, en su mayoría plantaciones y en menor medida remanentes de bosques naturales de estas especies. La mayor parte de los bosques se encuentran en los Salares de Pintados, Bellavista y Zapiga y en los alrededores de La Huayca y La Tirana. Algunas especies acompañantes en estas formaciones son Atriplex atacamensis (cachiyuyo), Caesalpina aphylla (retamo), Tessaria absinthiodes (brea), Euphorbia tarapacana y Tagetes grandulosa.

Las plantaciones más antiguas fueron efectuadas en los años 1930-1940 por un particular (Luis Junoy, empresario salitrero) y las mayores superficies fueron establecidas posteriormente por la Corporación de Fomento de la Producción (CORFO), mediante un amplio programa de forestación desarrollado en el período 1963-1972. Las últimas plantaciones fueron efectuadas por CONAF entre los años 1983 y 1986 (CONAF, 1997).

El drenaje de los suelos es subterráneo, con la excepción de escurrimientos superficiales ocasionales originados en el invierno altiplánico. Este movimiento de aguas subterráneas se ve interrumpido por la Cordillera de la Costa provocando un ascenso de las napas, lo que sumado al flujo capilar hacia la superficie que provoca la alta evaporación en esta, pasando a través estratos ricos en sales, mantiene a los salares activos en materia de desarrollo del estrato superficial salino, altamente cementado y formado por cloruros, sulfatos y carbonatos.

Las formaciones naturales de esta zona fueron severamente explotadas en el pasado como combustible para la minería de plata en los Siglos XVIII y XIX y después para la industria del salitre (nitratos de sodio y potasio) que se extraía de los salares en el Siglo XIX e inicios del Siglo XX. La disponibilidad de aguas subterráneas permitió también actividades agrícolas, que a mitad del Siglo XIX y principios del Siglo XX llegó a ser bastante intensa, empleando el sistema de canchones, consistente en fajas de terrenos de los cuales se quitaba el estrato salino de la superficie para realizar los cultivos.

En el año 1963, CORFO dio inicio al Programa Forestal - Ganadero cuyo objetivo era establecer plantaciones y posteriormente sobre este recurso introducir razas ovinas, 
bovinas y caprinas. Es así como entre los años 1965 y 1970 se plantan 13.814 ha, distribuidas en las localidades de Refresco, Salar de Bellavista y Salar de Zapiga, y en 1970 ya se mantenía una masa ganadera de más de 4 mil cabezas de alrededor de 10 diferentes razas (CONAF, 1997).

A mitad de los años 70 este plan concluyó y finalmente, en 1983, CORFO traspasa a CONAF la administración de las plantaciones. CONAF entre los años 1983 y 1985 establece 750 ha adicionales de plantaciones y se da inicio a un sistema de arriendo de talaje, en parcelas de 100 ha para una carga admitida máxima de 100 ovinos ó 50 caprinos (CONAF, 1997), sistema que se mantiene hasta ahora en la Reserva Nacional creada en 1987, con ganaderos provenientes de la precordillera y altiplano y de la pampa misma, en su mayoría de origen aymara.

El manejo actual de la Pampa del Tamarugal intenta compatibilizar la actividad ganadera con un manejo forestal, que permita en forma sustentable producir leña, carbón y madera (mueblería, parqué). Se suman actividades de investigación, turismo y otras. No obstante, el recurso existente presenta ciertas limitaciones para los fines productivos, dados por la calidad de los árboles y su estado sanitario.

La técnica de plantación empleada consistía en un hoyo de profundidad variable, de acuerdo al espesor de la costra salina, al fondo del cual se instalaba más de una planta para asegurar la supervivencia, y posteriormente se aplicaba riego por algunos meses, dependiendo de la profundidad de la napa. Tiempo después, en muchos casos el salar se cierra nuevamente en torno al tronco, resultando en un árbol parcialmente enterrado y de varios fustes.

A lo anterior se agregan la mortalidad de ejemplares, el escaso crecimiento y la baja producción de frutos, problemas originados en el severo ataque de insectos sobre, flores, frutos y semillas, como la polilla del fruto de tamarugo (Cryptophlebia saileri ), el bruco del tamarugo (Scutobruchus gasto) y el bruco de algarrobo (Rhiphibrucus picturatus).

Estas situaciones limitan el manejo forestal, para productos de valor, y restringe el uso ganadero. Ejemplo de esto es que la carga autorizada actual para los ganaderos, de 1 cabeza por hectárea, dista mucho de la que se planteaba inicialmente el Plan de CORFO, que era de 4 a 10 ovinos por hectárea.

En las restantes áreas de distribución de las especies del género en el país, con la excepción de algunas plantaciones de Prosopis alba, en las Región de Antofagasta, y de Prosopis chilensis, en las Regiones de Atacama y Coquimbo, las formaciones corresponden a bosques naturales remanentes de procesos de deforestación provocados por la actividad minera y el sobrepastoreo en los siglos pasados, y están representadas normalmente por formaciones abiertas de Prosopis chilensis, de escasa densidad, que hoy en general están bajo ganadería extensiva y uso forestal ocasional regulado por el Estado.

\section{ALGUNOS ANTECEDENTES DE CRECIMIENTO Y RENDIMIENTO EN CHILE}

En los primeros años de la década 1980-1990, INFOR desarrolló diversos estudios encargados por CORFO en la Pampa del Tamarugal. Barros y Wrann (1992) resumen algunos 
antecedentes de crecimiento y producción en formaciones de tamarugos y algarrobos.

\section{Parámetros Medios de Rodal}

Del catastro realizado por INFOR (1981) se obtienen los parámetros medios de rodal que se indican en el Cuadro $\mathrm{N}^{\circ} 8$.

\section{Cuadro $\mathrm{N}^{\circ} 8$}

PARÁMETROS MEDIOS DE RODAL EN FORMACIONES DE PROSOPIS

\begin{tabular}{|l|r|r|r|r|r|}
\hline Formación & \multicolumn{1}{|c|}{$\begin{array}{c}\text { Altura } \\
(\mathbf{m})\end{array}$} & $\begin{array}{c}\text { Diámetro } \\
(\mathbf{c m})^{*}\end{array}$ & $\begin{array}{c}\text { Densidad } \\
\text { (arb/ha) }\end{array}$ & $\begin{array}{c}\text { Diámetro } \\
\text { Copa } \\
(\mathbf{m})\end{array}$ & $\begin{array}{c}\text { Fustes } \\
\left(\mathbf{N}^{\circ}\right)\end{array}$ \\
\hline & & & & & \\
Plantación P. tamarugo & 7,1 & 9,8 & 54 & 8,1 & 6 \\
Plantación P. alba & 6,2 & 12,9 & 38 & 14,9 & 9 \\
Plantaciones mixtas & 8,9 & 19,5 & 23 & 16,4 & 6 \\
Bosques naturales P. tamarugo & 7,2 & 6,6 & 60 & 7,8 & 12 \\
& & & & & \\
\hline
\end{tabular}

*A 1 m de altura

(Fuente: Barros y Wrann, 1992)

Dos tercios de las plantaciones están en sectores con la napa freática a profundidades de 6 a $12 \mathrm{~m}$ de profundidad y un tercio en sectores con napa de 0 a $10 \mathrm{~m}$ de profundidad. La edad predominante de las plantaciones es 10 a 15 años.

\section{Relaciones entre Parámetros}

Un muestreo en plantaciones de tamarugo, en sectores con napa a 2 a $10 \mathrm{~m}$ de profundidad, permitió construir funciones de altura, de las cuales se desprenden las siguientes estimaciones:

Altura Total $(m)=-1,2410+3,2548$ * In Edad (años)

Relación que da aproximadamente $7 \mathrm{~m}$ a los 10 años, $10 \mathrm{~m}$ a los 35 años y $11 \mathrm{~m}$ a los 50 años.

Altura total $(\mathrm{m})=-6.7106+5,7086$ * In Diámetro $(\mathrm{cm})$

Relación que da aproximadamente $18 \mathrm{~cm}$ de diámetro para $10 \mathrm{~m}$ de altura, $35 \mathrm{~cm}$ para $14 \mathrm{~m}$.

Altura Total $(\mathrm{m})=-6,7252+3,641{ }^{*}$ In Área Proyección Copa $\left(\mathrm{m}^{2}\right)$

Relación que da aproximadamente $26 \mathrm{~m}^{2}$ para $5 \mathrm{~m}$ y $102 \mathrm{~m}^{2}$ para $10 \mathrm{~m}$. 


\section{Producción de Forraje}

Estimaciones de producción de follaje y frutos en plantaciones de tamarugo y algarrobo ( $P$. alba) entregan resultados muy dispares, dada la alta variabilidad de edades, tamaños, sitios y otros factores. Como ejemplo, en el Cuadro $N^{\circ} 9$ se muestran cifras de producción media de forraje para las temporadas 1981 y 1982.

\section{Cuadro $\mathrm{N}^{\circ} 9$}

PRODUCCIÓN MEDIA DE FORRAJE POR ÁRBOL EN LAS PLANTACIONES PARA LOS

\begin{tabular}{|c|c|c|c|c|c|c|}
\hline \multirow[t]{2}{*}{ Plantación } & \multicolumn{2}{|c|}{$\begin{array}{c}\text { Follaje } \\
\text { (kg) }\end{array}$} & \multicolumn{2}{|c|}{$\begin{array}{c}\text { Frutos } \\
\text { (kg) }\end{array}$} & \multicolumn{2}{|c|}{$\begin{array}{c}\text { Total } \\
\text { (kg) }\end{array}$} \\
\hline & 1981 & 1982 & 1981 & 1982 & 1981 & 1982 \\
\hline Algarrobo & 21 & 88 & 10 & 29 & 31 & 117 \\
\hline Tamarugo & 42 & 63 & 35 & 42 & 77 & 105 \\
\hline
\end{tabular}

(Fuente: Barros y Wrann, 1992)

Si estas cifras se expanden a la superficie de una hectárea, empleando las densidades medias del Cuadro $N^{\circ} 8$, de 54 arb/ha para tamarugo y 38 arb/ha para algarrobo, se obtienen 6.318 y $3.990 \mathrm{~kg} / \mathrm{ha}$, respectivamente, en el caso del año 1982.

\section{UTILIZACIÓN}

El aprovechamiento de algarrobos y mezquites por el hombre como forraje, combustible, construcciones y alimento humano es de muy antigua data. En la Pampa del Tamarugal en Chile existen evidencias, en sitios arqueológicos como Aragón y Tiliviche, de pueblos recolectores y cazadores, nómades inicialmente y sedentarios después, que se remontan a 5 a 7 mil años AC (CONAF, 1997).

Felker (2009) comenta que posiblemente no hay otras especies con el potencial de generar desarrollo económico en áreas muy pobres, asoladas e inhóspitas como las de la Región Saheliana en África, el Medio Este y los desiertos de India y Pakistán. Especies de raíces profundas, fijadoras de nitrógeno, resistentes a calor, sequía y salinidad, que prosperan bajo las más extremas condiciones de sitio y ofrecen valiosos productos y servicios, son una oportunidad sin paralelo para las zonas áridas y semiáridas. Este autor destaca la calidad de los frutos alimenticios y la madera de alta estabilidad dimensional para productos valiosos como muebles y pisos entre los más importantes potenciales de estas especies, además de los beneficios ambientales como sombra, protección y mejoramiento de suelos, ornamentación y otros.

Pasiecznik et al. (2001), resaltan los múltiples productos dados por la madera, los frutos, las hojas, mieles y ceras, gomas, curtientes, tinturas y fibras, medicinas y beneficios ambientales. 


\section{Madera}

La madera es probablemente el producto más importante, sea para combustible o para usos estructurales o madera aserrada. Como combustible puede ser empleada en forma directa o para producir carbón, mientras que la madera se puede usar como postes y estacas o para aserrío. Esto depende de las especies y su manejo, hay especies arbustivas que solo generan cantidades limitadas de combustible y carecen desde luego de valor para usos estructurales, y hay especies arbóreas que con sus troncos y ramas son importantes fuentes de combustible y madera para las poblaciones locales.

La madera de estas especies es un combustible de gran calidad, con un poder calorífico medio cercano a $5.000 \mathrm{Kcal} / \mathrm{kg}$, por ejemplo desde $4.200 \mathrm{Kcal} / \mathrm{kg}$ para Prosopis alba a 5.065 $\mathrm{Kcal} / \mathrm{kg}$ para Prosopis tamarugo. Arde bien en estado verde o seco y contiene hidrocarbonos aromáticos, lo que la hace muy aceptada como leña para barbacoa que tiene alta demanda e interesantes precios en países como Argentina y USA. El carbón obtenido de estas maderas es también de alta calidad y puede ser producido tan fácilmente con madera verde como seca, en hornos tradicionales, en 2 a 4 días y con un rendimiento en peso de 10 a $20 \%$ con madera verde. Otro aspecto positivo es la facilidad de rápido rebrote de los árboles después de severas y repetidas cortas, sin detrimento del estado sanitario de los ejemplares.

La madera central o durámen es fuerte, dura, pesada y durable, su peso específico varía con las especies y es en general de 0,7 a 1,0, la densidad se mueve de 700 a $1.200 \mathrm{~kg} / \mathrm{m}^{3}$, normalmente la más pesada es Prosopis tamarugo, seguida por Prosopis chilensis, P. pallida y $P$. glandulosa. Tiene una relativa mayor estabilidad dimensional frente a otras especies, lo que se traduce en bajas contracciones y rajaduras. El corazón es rojo oscuro o café oscuro, a diferencia de la albura generalmente amarilla.

La madera de ramas largas y rectas, o de retoños de corta anterior, es usada para postes de cerco y mango de herramientas muy durables, y la madera aserrada puede ser usada en partes de casas e incluso en mueblería fina (Argentina, USA) y en elegantes pisos de parqué (Chile, USA). La madera aún siendo dura y densa, es trabajable sin problemas y acepta buena terminación.

\section{Fruto}

Las legumbres, vainas o capes, distintos nombres que se da a estos frutos, tienen altos contenidos de azúcar, carbohidratos y proteínas, por lo que históricamente han sido fuente de alimentos para las poblaciones en donde estas especies se encuentran. En tiempos más recientes han adquirido más importancia como alimento para ganado. Su valor nutritivo y su tamaño varían ampliamente con las especies. El sabor del mesocarpo del fruto varía desde agrio y amargo a dulce, y la suculencia también lo hace, desde frutos secos y fibrosos a suculentos y más dulces.

Frutos de especies de la Sección Algarobia contienen 7-22 \% proteína, 30-75\% carbohidratos, $11-35 \%$ fibra cruda, $1-6 \%$ grasa y $3-6 \%$ cenizas. No obstante esto es muy variable entre especies. 


\section{Hoja}

El consumo de la hojas varía también según las especies y los diferentes animales que las pueden comer. Algunas pocas especies tienen hojas palatables y son un valioso recurso forrajero. Las especies de Asia y África tienen follaje palatable, pero solo el de unas pocas americanas es fácilmente consumido por todo tipo de ganado. Las tres principales especies forrajeras en base al follaje son Prosopis africana, $P$. cineraria y $P$. tamarugo.

Los tallos tiernos y las hojas jóvenes de todas las especies son consumidos en forma ocasional por el ganado, especialmente cuando las alternativas de forraje son limitadas. Las hojas de todas las especies son comidas solo cuando no hay forraje alternativo disponible. Follaje inmaduro y hojas caídas y secas tienen mayor palatabilidad que material maduro y fresco. En el caso de las especies más palatables, las hojas pueden ser consumidas directamente del árbol o desde ramas cortadas para estos efectos. Los sistemas de manejo en general incluyen esta última práctica hasta por tres veces al año con Prosopis cineraria.

La composición del follaje no varía mayormente entre las especies. En el caso de Prosopis cineraria, especie palatable, las hojas contienen 11 a $18 \%$ de proteína cruda, 13 a 22 $\%$ de fibra cruda, 43 a $59 \%$ de extracto de nitrógeno libre, 6 a $12 \%$ de cenizas, 1,5 a 3,8 \% de calcio y 0,3 a $1,8 \%$ de fósforo. Las hojas de Prosopis juliflora en tanto, no palatables, contienen 14 a $22 \%$ de proteína cruda, 21 a $23 \%$ de fibra cruda, 43 a $50 \%$ de extracto de nitrógeno libre, $1,5 \%$ de calcio y $0,2 \%$ de fósforo.

\section{Miel y Cera}

Las flores son un buen recurso melífero, producen abundantes cantidades de néctar y polen por períodos de tiempo prolongados y atraen así a los insectos polinizadores. Las principales especies de abejas, con los más largos rangos de vuelo, están entre los agentes polinizadores. La miel de Prosopis es amarillo claro, generalmente de buena calidad, con un gusto agradable y un aroma tenue.

La apicultura existe en la mayor parte de las áreas donde los Prosopis son nativos y están ampliamente distribuidos y en diversos lugares en los que se los ha introducido.

México es el mayor exportador de miel, principalmente nominada miel de acacia, pero buena parte de esta proviene de mezquite. Grandes cantidades de miel de alta calidad fueron exportadas por años desde Hawaii, con una producción basada en extensas áreas donde Prosopis pallida fue introducido.

\section{Goma}

La goma es exudada por heridas naturales en la corteza como un mecanismo de defensa, pero esta exudación puede ser estimulada mediante heridas provocadas. Las gomas de estas especies son solubles en agua, liquida y amarilla cuando fresca, y se solidifica y oscurece lentamente. 
La goma ha sido producida tradicionalmente con especies de acacias, en particular de Acacia senegal, cuya goma es la referencia en calidad para cualquier comparación. Los Prosopis producen goma comparable con la de las especies que normalmente se usan con este fin y, en el caso de Prosopis juliflora, esta es químicamente casi idéntica a la de Acacia senegal.

La goma es usada ampliamente como aditivo de alimentos, emulsionantes, espesantes, como materia prima para adhesivos y en preparaciones farmacéuticas. En India se afirma que la goma es amarga y se la usa crecientemente en fabricación de textiles y adhesivos. La recolección de goma de Prosopis juliflora es una actividad importante en zonas de India, los árboles son cosechados en la época seca y un hombre puede obtener alrededor de $1 \mathrm{~kg}$ por jornada.

\section{Curtientes}

La corteza contiene 14 a $16 \%$ de taninos y el contenido de este compuesto en diferentes partes de los árboles para diferentes especies varía de 6 a $20 \%$. Los taninos obtenidos de la corteza, junto con los que se encuentran en la madera y los que se obtienen de extracto de los frutos, son usados en el curtido de cueros. Los taninos eran extraídos de la corteza y otras partes del árbol hirviendo el material en agua, actualmente se los extrae mediante arrastre de vapor.

\section{Fibra}

Empleando raíces descortezadas se elaboraban en Norteamérica fuerte cuerdas y lazos. Fibras obtenidas de la corteza interior eran utilizadas con los mismos fines y también para cestería.

\section{Tinturas}

De las raíces se obtienen extractos colorante, café-púrpura, empleados para teñir algodón y otros materiales. La corteza y las gomas se usan para producir pinturas y tintes y también en cosmética y elaboración de champú.

\section{Usos Medicinales}

En las áreas de distribución de estas especies son muchas las aplicaciones medicinales de extractos de distintas partes de los árboles. Hay diversas dolencias tratadas con extractos de de corteza y de hojas; infecciones de la garganta y bronquitis, enfermedades internas, parásitos y problemas urinarios, y problemas de la piel, como dermatitis, infecciones y parásitos.

En Asia las flores se usan para prevenir abortos, extractos de corteza para el tratamiento de la lepra, la disentería, temblores y reumatismo. Humo de hojas para curar infecciones oculares y extractos de hojas para mordeduras de serpientes y picaduras de escorpiones. Similares usos son reportados en África. 
En Sudamérica, preparaciones de brotes tiernos y yemas se emplean para la conjuntivitis, preparaciones con hojas para fracturas, cálculos biliares, dolores de oídos y también para mordeduras de serpientes y picaduras de escorpión.

En Norteamérica, se preparan infusiones de distintas partes de los árboles; de hojas, yemas y gomas, para dolencias oculares; de corteza, hojas y gomas, como laxantes, purgantes y vomitivos; soluciones de goma, para irritaciones de la garganta y afecciones respiratorias; hojas, corteza y gomas, para diarrea y desórdenes estomacales, indigestiones y ulceras; y savia o gomas, para curar heridas y afecciones de la piel.

Se ha aislado diferentes compuestos químicos que explican estos usos medicinales, como distintos aminoácidos libres, flavonoides, alcaloides y otros.

\section{REFERENCIAS}

Barros, S. y Wrann, J., 1992. El Género Prosopis en Chile. En: Ciencia e Investigación Forestal, Vol $6 \mathrm{~N}^{\circ}$ 2. pp 295 - 334. Instituto Forestal, Chile.

Beresford - Jones, David G., 2004. Pre-Hispanic Prosopis-Human Relationships on the South Coast of Peru: Riparian Forests in the Context of Environmental and Cultural Trajectories of the Lower Ica Valley. Magdalene College, University of Cambridge. 3. The Genus Prosopis on the South Coast of Peru.

Burkart, A., 1976. A Monograph of the Genus Prosopis (Leguminosae subfam. Mimosoideae). Journal Arnold Arboretum 57: 217-249 and 450-525.

En línea: http://www.botanicus.org/item/31753002407929.

CONAF, 1997. Plan de Manejo Reserva Nacional Pampa del Tamarugal. Corporación Nacional Forestal. Chile 107 p. y Anexos.

Enciclopedia de la Flora Chilena, 2010. Prosopis L.

En línea: http://www.florachilena.cl/Niv_tax/Angiospermas/Ordenes/Fabales/Fabaceae/ Prosopis/prosopis.htm. Consulta marzo 2010.

FAO, 2010. Evaluación de los Recursos Forestales Mundiales (FRA-2010)

En línea: http://www.fao.org/forestry/static/data/fra2010/KeyFindings-es.pdf. Consulta marzo 2010.

Felker, Peter, 2009. Unusual Physiological Properties of the Arid Adapted Tree Legume Prosopis and theirApplications in Developing Countries. Chapter 9.

En linea: http://sites.google.com/site/petersprosopismesquitesite/documents. Consulta marzo 2010.

ICBN, 2005. International Code of Botanical Nomenclature (VIENNA CODE). Electronic version of the original English text. Adopted by the Seventeenth International Botanical Congress. Vienna, Austria, July 2005. Prepared and edited by J. Mc NEILL, Chairman, F. R. Barrie, H. M. Burdet, V. Demoulin, D. L. Hawksworth, K. Marhold, D. H. Nicolson, J. Prado, P. C. Silva, J. E. 
Skog, J. H. Wiersema, Members. N. J. Turland, Secretary of the Editorial Committee. 2006. En línea http://ibot.sav.sk/icbn/main.htm. Consulta marzo 2010

INFOR, 1981. Studio de las Especies del Género Prosopis en la Pampa del Tamarugal. Tomo II Clasificación, Características y Cartografía de los Bosques de Prosopis. Instituto Forestal, Santiago, Chile. pp 102. No publicado, Trabajo realizado para CORFO-SACOR.

INFOR, 1986. Mejoramiento Genético Prosopis. Tomo I Localización de las Principales Superficies Boscosas Naturales y Plantadas de Algarrobo y Tamarugo entre la I Región y la región Metropolitana. Trabajo realizado para Proyecto CONAF/PNUD/FAO/CHI-83-017. Actividad I-1.3.1. Santiago, Chile. pp 277.

INFOR, 2009. Anuario Forestal 2008. Sede Metropolitana, Instituto Forestal, Chile. pp 161.

Köppen, 1900. Clasificación Climática. En línea: http://es.wikipedia.org/wiki/Archivo:World_ Koppen_Map.jpg. Consulta febrero 2010.

Pasiecznik, Nick, Peter Felker, P.J.C., Harris, L.N. Harsh, G. Cruz, J.C., Tewari, K. Cadoret and L.J. Maldonado. 2001. The Prosopis juliflora-Prosopis pallida Complex: A Monograph. HDRA, Coventry, UK.

En línea http://www.researchintouse.com/nrk/RIUinfo/outputs/R7295_Prosopis_Monograph. pdf. Consulta marzo 2010.

Stevens, P. F., 2001. Fabaceae. Angiosperm Phylogeny Website. Version 7 mayo 2006.

En línea: http://www.mobot.org/MOBOT/Research/APweb/orders/fabalesweb.htm\#Fabaceae. Consulta marzo 2010

Wikipedia, 2010. Wikipedia, La Enciclopedia Libre.

En línea: http://es.wikipedia.org/wiki/Fabaceae. Consulta marzo 2010. 
